\title{
Relative ecological and biological indicator values of plum and prune cultivars
}

\author{
Surányi, D. \\ NARIC Fruit Research Institute, Fruit Station, Cegléd H- 2700, PO Box 33.
}

\begin{abstract}
Summary: The study was conducted to compare historical plums, gene collections, and is currently cultivated and recent perspective varieties from the author. The object of the study was the relative ecological Borhidi's figures and classification of varieties under the new definition, as the relative biological values. There were 11 figures no one in particular affect the data of the plums grown in importance as TB, WB, RB, LB, and the values are relative biological value (OP, FR, SS, and DR). The specificity of each indicator was different, but in general the importance and specific breeds was associated with. The SB (salt figures) is not proved informative, partly because small data in the literature, on the other hand, had little to their own observations as well. The gene bank of Cegléd is now third-generation (1951-1972, 1973-1991, since 1992) kind of collection, during which many aspects have changed climatic conditions: cold winter eased the strictness, but has increased the threat of spring frost advection. The relative biological scores markedly influenced around flowering extreme weather (dry, windy weather and so flowering in within 2-3 days), optimal conditions of the plum pox virus vectors and of course the presence of fruit and foliage harmful fungi. It see to be, in the case of semi-wild and wild fruit species - are possible with similar comparative analyzes, and hopefully will in feral forms, culture - as we have seen previously (Surányi 2000 and 2006). In the continuation analysis of the natural vegetation and cultural context of the complex multifactorial factors will be carried out more easily, according to the relative value figures, as well as rootstock effects and plantation's habitat studies, and even the most phytotechnical evaluation of interventions.
\end{abstract}

Keywords: plums, relative ecological and biological figures, comparative studies of cultivars

\section{Introduction}

The plum is one of the oldest domesticated fruit species, yet relatively little-known archaeological site, although the evidence is, however, rich archeobotany. The Carpathian Basin is a different situation because the local outcrops of rescue excavations archeobotanical always received great emphasis. These data carry cultural evolution introduced historical information is, of course, the archaeological ages; ethnic groups often exchanger activity was also documented (Gyulai 2001). The natural conditions of the natural environment taking into account the conversion of a long process result (Surányi 1985, Roach in 1985, Visy 2003).

The plum and geographic large regions importance of really raises the Prunus domestica (reciprocal) parental partners in the Carpathian Basin resident, that is, blackthorn and cherry plum area meets reach the Caucasus region of (Rybin 1935, 1936 and 1962), Central Europe and Balkan (Schwanitz 1973, Terpó 1974, Larcher 1980, Faust - Surányi 1997).

The origin of species, their genetic and biological properties of the characters assume the specific ecological needs (Faust et al. 2011). In a number of branches of botany ecological evaluation is not new, examples of which can be found in the literature on Hungarian language (Soó 19641985, Zólyomi 1964, Précsényi 1986, Simon 1988 and Borhidi 1993).

Over the last decade, based mainly on works of Simon $(1988,1991)$ and Borhidi $(1993,1995)$, individual ecological indicator values have been established (Surányi 2000), and applied for the varieties prepared in the national cultivar catalogue (Pernesz 2013), pomological handbooks (Soltész 1998) and former pomological works (cf. Surányi 2002). This study presents an expanded and updated version of that one published in Kanitzia (Surányi 2006), and a summary of Hungarian fruit cultivars in Acta Bot. Hung. (Surányi 2014).

The expression of the ecological experience in form of relative indicator values is not a new classification experiment to compare the ecological species. In this paper we consistently use Borhidi's $(1993,1995)$ fundamental work on the ecological values of the indigenous flora. At first, Iversen (1936) applied relative indicator values for characterising salt-resistance of coastal plants, suggesting a three-grade scale. Ellenberg $(1950,1952)$ worked out the ecological indicator values of a larger number of meadow plants and different weeds for several ecological factors and the first experiment for applying these indicator values in classifying plant communities. Ellenberg (1963) applied 5 -grade scales and the moisture scale was amplified later to a 10 -grade scale.

The development of the indicator values, an important contribution was made by Zólyomi’s TWR-system (1964) and that improved their staff (Zólyomi et al. 1967).

The TWR-system consisted of a 10-grade temperature scale (T), an 11-grade water content or soil moisture scale (W) and a 5-grade soil reaction scale (R), which was worked out for 1.400 native species of the Hungarian flora and weeds 
(Kárpáti 1978) and with some critical taxonomic groups (Borhidi 1969). The TWR formed an ecological reference system for plant communities and to place a multidimensional ecological space (cf. Précsényi, in Zólyomi 1964, Zólyomi and Précsényi 1979, cit. Borhidi 1993, Zólyomi 1987).

Ellenberg (1974) elaborated ecological behaviour indicator values with regard to the seven main environmental factors; three of them are climatic ones: temperature $(\mathrm{T})$, light (L), and continentality (C), further three indicators related to soil factors, i.e. moisture or water supply $(\mathrm{F})$, acidity or Soil reaction $(\mathrm{R})$ and nitrogen supply $(\mathrm{N})$, the salinity has been recently actualised (Ellenberg et al. 1991). Although the indicator values of Ellenberg were not used by the Hungarian botanists, it had been included into the Synopsis of Soó (1964-1985): the TFRN-values of Soó can be obtained by dividing Ellenberg's figures. Kovács (1979) elaborated Ellenberg's indicator values of 1.300 plant species of Romania and a register of other biological characteristics, too. Borhidi $(1993,1995)$ found the ecological indicator values of the Hungarian flora in the following order, which we applied in a recent study of pomological species. In the following, we take the figures as defined in Borhidi's (1993, $1995)$ study, as well as to extend the cultivated fruit varieties in the Hungarian cultural flora.

This study of the species plum (Prunus insititia, $P$. cerasifera, $P$. domestica, $P$. x italica convar. pomariarum, P. x italica convar. ovoidea, $P$. x italica convar. mamillaris, P. x italica convar. claudiana, $P$. syriaca and $P$. salicina) collected (genebank) of old and recent (wild) include an analysis cultivars, complete with Ellenberg-Borhidi system relative measurement of four biological tool (open pollination, frost resistance, disease resistance and sensitivity sharka virus) (cf. Gyúró 1974 and Soltész 1998).

The relative ecological and biological values are based on a large number of ecological sources and own data. The figures came from Ellenberg - Borhidi (485 varieties are not individually labeled with the relevant data) from the following sources: Faust (1989), Kozma et al. (2003), Mándy (1963), Gardner - Bradford - Hooker (1952), G. Tóth (1997), Jávorka - Soó (1951), Kárpáti - Terpó (1971), Kobel (1954), Kozma et al. (2003), Mándy (1963), Larcher (1980), Papp (2003 and 2004), Papp - Tamási (1979), Porpáczy (1964), Ramming - Cociu (1991), Raunkiaer (1905), Soltész (1998 and 2014), Surányi (1985, 1986, 2000, 2006, 2011, 2013 and 2014), Tomcsányi (1979), Vondraček (1975) and V. Németh (1986).

The new, additional, so-called relative biological indicators in determining the source of these included: Bellini et al. (1982), Bereczki (1877-1887), Bordeianu et al. (1965 and 1969), Brózik (1960), Brózik - Nyéki (1975), Crane - Lawrence (1956), Csöbönyei (1957-1970), Dahl (1935), Dermine - Liard (1957 and 1978), Faust - Surányi (1997), G. Tóth (1997), Gyuró (1974 and 1990), Hedrick et al. (1911), Jávorka - Soó (1951), Knight (1969), Kobel (1954), Kozma et al. (2003), Mándy (1963), McGregor (1976), Nicotra et al. (1983), Nyéki (1980), Nyéki - Soltész (1996), Holb et al., (2007), Nyéki - Soltész - Szabó (2012),
Papp (2003 and 2004), Pernesz (2013), Porpáczy (1964), Ramming - Cociu (1991), Röder (1940), Soltész (1998 and 2014), Surányi (1985, 1986, 1990a and 1990b, 1991, 19912015, 2002, 2005, 2006, 2009, 2013 and 2014), Surányi Erdős (2004), Szabó (1989), Taylor (1949), Tomcsányi (1960 and 1979), Tóth (1957, 1967, 1968), Tóth - Erdős - Surányi (1971-1990), Tóth - Surányi (1980) and Vondraček (1975).

\section{Materials and methods}

There are 485 different plum cultivars which have different taxonomic character in Material and Methods. These relative values determined on the basis of the ecological information of plums for references to literary sources... The definition of Borhidi's ecological figures is following (1993 and 1995).

TB: The relative temperature figures reflecting the heat supply of the habitats where the species occur (mainly based on the distribution according to the latitudinal vegetation zones and altitudinal belts). The temperature figures of Ellenberg's (1974) 9-grade scale (T) applied by Borhidi (B) (1995) to the Hungarian flora and by Surányi (2014) to the Hungarian culture's flora. The relative figures indicate the following heat-climate belts or the corresponding microclimate conditions:

5. Montane mesophilous broad-leaved forest belt

6. Submontane broad leaved forest belt

7. Thermophilous forest or woodland belt.

WB: The relative moisture figures (occurrence in relation to soil moisture or water table) according to the 12-grade F-scale of Ellenberg (1963). The scale is very similar to the W-scale of Zólyomi (1964), but the water plants have a more detailed categorization, as follows:

4. Plants of semidry habitats

5. Plants of semi humid habitats, under intermediate conditions

6. Plants of fresh soils

7. Plants of moist soils not drying out and well aerated.

RB: Reaction figures, according to the nine-grade Ellenberg's scale (1952), reflect to the occurrence of the plants in relation of the soil reaction of the habitats (Tüxen - Ellenberg 1937). In the 5-grade Zólyomi's (1987) scale calciphilous and salt tolerant or even halophilous plants are equally treated as basiphilous plants. Here the two groups are differentiated by their positive or negative salt figure category. A comparison of the reaction value scales according to Ellenberg's (1952) versus Zólyomi's classification (1987) was carried out by Pichler - Karrer (1991). The correspondent degrees are:

4. Plants of moderately acidic soils

5. Plants of slightly acid soils

6. Mostly on neutral soils but also in acid and basic ones, generally widely tolerant, more or less indifferent plants

7. Basifrequent plants, mostly on basic soils.

NB: Nitrogen figures according to Ellenberg's 9-grade scale (1974), based on the occurrence in relation to the ammonia and nitrate supply of the habitats, which received 
Borhidi (1995) then Surányi (2014) too. These are degrees:

4. Plants of submesotrophic habitats

5. Plants of mesotrophic habitats

6. Plant of moderately nutrient rich habitats.

LB: Light figures according to Ellenberg's 9-grade scale (1974), based on the occurrence of plants in relation to relative light intensity during summer time. Degrees are follows:

4. Shadow-half shadow plants; photosynthetic minimum between 5 and $10 \%$ relative light intensity

5. Half shadow plants receiving more than $10 \%$ but less than $100 \%$ relative light intensity

6. Half shadow-half light plants; photosynthetic minimum between 10 and $40 \%$ relative light intensity

7. Half light plants, mostly living in full light but also shadow tolerant.

KB: Continentality values according to Ellenberg's ninegrade scale (1952) based on the main distribution of plants according to degree of continentality of the general climate (see Meusel - Schubert 1972) with emphasis on maximum and minimum temperature. Degrees following:

4. Suboceanic species, mainly in Central Europe but reaching to East

5. Intermediate type with slight suboceanic-subcontinental character

6. Subcontinental, main area in eastern Central Europe

7. Continental-subcontinental species main area in EastEurope.

SB: Salt figures for indicating plant occurrence in relation to the salt concentration of the soils in a 9-grade scale, according to Scherfose (1990). Literary sources of ecological indicators are included in the Introduction, because breakdown by type of detail is not possible. The salt figures at least, developed to the SB. The toxic salt content is generally perceived afterwards, when the trees have been damaged:

0. Halophob species not occurring in salty or alkalic soils

1. Salt tolerant plants but living mainly on non-saline soils.

It was developing new added relative value numbers that have been introduced in the fruit-bearing species. We first presented in open pollination, the flower buds and bark frost sensitivity and significance for plums and prunes main concern viruses Sharka sensitivity and susceptibility to disease pathology (monilia, polystigma, clasterosporium, taphrina) characterization among the plum cultivars.

$\mathbf{O P}=$ Measuring of open pollination

1. over $35 \%$ of open pollination

2. $20-35 \%$ of open pollination

3. $2-20 \%$ of open pollination

4. below $2 \%$ of open pollination.

$\mathbf{F R}=$ Degree of frost resistance

1. frost tolerant (over $5 \%$ of flower bud and bark damage)

2. moderately frost sensitive (15-40\% of damages)

3 . frost sensitive (about $50 \%$ of frost damages).

$\mathbf{S S}=$ Relative value of Sharka virus sensitivity
1. resistant to Sharka ( $0=$ no symptoms and presence)

2. tolerant to Sharka (no symptoms, or only in the leaves)

3. susceptible (largely symptomatic leaves and fruits)

4. very sensitive (symptomatic of the whole tree).

$\mathbf{D R}=$ Measuring of disease resistance

1. resistant to disease $(0=$ no symptoms on the trees $)$

2. moderately sensitive (cc. $30 \%$ of leaves or fruit symptoms)

3. sensitive (over $50 \%$ of leaf symptoms and fruit falling).

In this study we wanted to choose, whether it is possible in an economic species, though several taxa botanical species and under species the representatives of the ecological and biological differences between cultivars characterization according to Ellenberg - Borhidi - Surányi’s modified based on the relative figures. The results are shown in summing table; we assume that the cultivars will be easier of origin and economic-botanical view can be evaluated, increasing the effectiveness of plum cultivation.

\section{Results and discussion}

There were suitable for comparing the plum varieties based on 485 relative ecological figures of plums (Borhidi 1995), towards also a large number of data and its own observations, the relative biological indices. Since the beginning of studies, in particular, increased numbers can be expressed in value relative information (as ecological figures) of importance: due to climate change because of the extreme weather, the lack of rainfall actual vegetation - growing without irrigation, drought-tolerant cultivars of plums and role increase. Climate change impacts not only effects because of new pathogens, pests and dangers roof role in the change (increase can be observed more) plum cultivation - a series of new problems brought to light.

Although it is very difficult to prove the following relevantly, but experience shows that the largest number of varieties can change your reaction on the environment. So that no less - and therefore for this reason - the physiognomic character of plums too. Increasingly drier due to weather due to the increasing weight vector (aphids) organisms cause problems of the viral disease, or wet vegetation and fungal diseases and plum fruits mechanical damage (cracking). In 2014 it was almost impossible to defend in times of torrential rains and the thin-skinned and high sugar content varieties.

Since it was not possible types of representative taxa (P. cerasifera, $P$. insititia, $P$. domestica, four convarietas of P. italica, $P$. syriaca, $P$. salicina, as well as some American and other hybrid species, etc.) are statistically correct way compare (sort of like varieties and the order of repetition), so some varieties listed in Table 1 were carried out only to measures of individual comparisons. Earlier studies have been faced with these difficulties (Surányi 2000, 2006 and 2014). Still, there are several ways we tried to evaluate the fruit species, that is not only used in Ellenberg and Borhidi's figures, but Soó (1964-1985), Zólyomi et al. (1967), Simon 
(1988 and 1991) and Kovács (1979) also tried to evaluate the concept of fruit growing (that is in our fruit flora) cultivars. Although the literature cited authors examined all the natural species, varieties produced also tried to extend it. Finally, the Borhidi's relative ecological indicators found to be satisfactory analysis of the varieties (Surányi 2006 and 2014) (Table 1 and 2), which extended its biological figures.

The main conclusions were as follows:

1. The characterization of the plum cultivars are suitable values: relative temperature figures $(\mathrm{TB})$, relative moisture figures (WB) and light figures (LB).

But that does not mean the second nitrogen figures (NB), soil reaction figures $(\mathrm{RB})$ and continentality values $(\mathrm{KB})$ are insignificance.

3. The salt figures (SB) - in Ellenberg-Borhidi's system - according to the species natural to use, but varieties in Prunus the new and further analyzes are required. SB values are not sensitive enough.

4. The figures relate to the value of open pollination of cultivars (OP), degree of frost resistance (FR), - sharka virus sensitivity (SS) and the grade of disease resistance (DR) was evaluated and sensitivity of a quick overview.

5. As continuation of this work is mainly apricot, apple, pear and peach cultivars usable seen their economic-botanical evaluating, with all the comments, cabbage, which is valid for the plum varieties as well.

6. Apparently, among the cultivated strawberry cultivars (cf. Surányi 2005 and 2014), this form of the 11 least-used figure of the salt figures (SB) from the fruit species for each species at the level of the same can be said (Surányi 2014).

7. In the case of semi-wild and wild fruit species - are possible with similar comparative analyzes, and hopefully will in feral forms, culture - as we have seen previously (Surányi 2000 and 2006).

8. In the continuation analysis of the natural vegetation and cultural context of the complex multifactorial factors will be carried out more easily, according to the relative value figures, as well as rootstock effects and plantation's habitat studies, and even the most phytotechnical evaluation of interventions.

Table 1. Relative ecological indicator values of plum cultivars

\begin{tabular}{|c|c|c|c|c|c|c|c|c|c|c|c|}
\hline Species, cultivar & TB & WB & $\mathrm{RB}$ & $\mathrm{NB}$ & LB & $\mathrm{KB}$ & SB & $\mathrm{OP}$ & FR & SS & DR \\
\hline Abundance & $6-7$ & 5 & $5-6$ & 5 & 6 & 5 & 0 & 3 & 3 & $2-3$ & 3 \\
\hline Ageni & 6 & 5 & 5 & 5 & 6 & 5 & 0 & 3 & $1-2$ & 2 & 2 \\
\hline Ageni 698 & 6 & $5-6$ & 5 & $4-5$ & 6 & 5 & 0 & 3 & $1-2$ & 2 & 2 \\
\hline Ageni 707 & 6 & $5-6$ & 5 & $4-5$ & 6 & 5 & 0 & 3 & $1-2$ & 2 & 2 \\
\hline Alanvay korai & $5-6$ & 5 & 5 & 5 & $5-6$ & $5-6$ & 0 & 3 & $2-3$ & 2 & 3 \\
\hline Albatros & $5-6$ & $5-6$ & 5 & 5 & 6 & $5-6$ & 0 & $2-3$ & 1 & 2 & 2 \\
\hline Albion & $5-6$ & 6 & 5 & 5 & 5 & $5-6$ & 0 & 4 & 2 & 2 & 1 \\
\hline Althann ringló & $5-6$ & $6-7$ & $4-5$ & 5 & $5-6$ & $5-6$ & 0 & 3 & $1-2$ & 3 & 2 \\
\hline Althann ringló Bb. 94 & $5-6$ & $6-7$ & $4-5$ & 5 & $5-6$ & 6 & 0 & 3 & $1-2$ & $2-3$ & 2 \\
\hline Altländischer Saure Zwetsche & $5-6$ & 6 & 5 & 5 & $5-6$ & 6 & 0 & 4 & $2-3$ & 2 & 3 \\
\hline Altländischer Späte Zwetsche & $5-6$ & 6 & 5 & 5 & $5-6$ & 6 & 0 & 4 & $2-3$ & 2 & 3 \\
\hline Alutscha & $6-7$ & 6 & $5-6$ & $5-6$ & 5 & 6 & $0-1$ & 4 & 1 & $1-2$ & $1-2$ \\
\hline Angoulême-i ringló & 6 & $5-7$ & 5 & 5 & 6 & 6 & 0 & 3 & 2 & 2 & 2 \\
\hline Asatan & $5-6$ & 6 & $5-6$ & 6 & $5-6$ & 6 & $0-1$ & $2-3$ & 2 & $1-2$ & $1-2$ \\
\hline Áttetsző ringló & $5-6$ & 5 & 5 & $4-5$ & 6 & $5-6$ & 0 & 3 & 2 & 2 & $2-3$ \\
\hline Auerbacher & 6 & 6 & 6 & $5-6$ & 6 & $5-6$ & 0 & 2 & 2 & 3 & 2 \\
\hline Augusztinka & $6-7$ & 6 & 6 & 6 & 6 & $5-6$ & 0 & 3 & 2 & 2 & 1 \\
\hline Avalon & $5-6$ & $6-7$ & 5 & 5 & $5-6$ & 6 & 0 & 3 & $2-3$ & 2 & 2 \\
\hline Barackszilva & 6 & $5-6$ & 5 & 5 & $5-6$ & 6 & 0 & 4 & 3 & $2-3$ & $2-3$ \\
\hline Barna Lujza & 6 & 6 & $5-6$ & $5-6$ & 5 & 6 & 0 & $2-3$ & 2 & $1-2$ & 3 \\
\hline Bassett & 5 & 5 & 5 & $5-6$ & $5-6$ & $5-6$ & 0 & 4 & 3 & 3 & 3 \\
\hline Bazalicza szilvája & 5 & $5-6$ & 5 & 5 & 6 & 6 & 0 & 4 & $1-2$ & $1-2$ & $1-2$ \\
\hline Bärtschis Frühzwetsche & $5-6$ & $5-6$ & $5-6$ & 5 & $5-6$ & 6 & 0 & 3 & $1-2$ & $1-2$ & 2 \\
\hline Behren's királyszilva & 5 & 5 & 5 & $5-6$ & $5-6$ & 5 & 0 & 2 & 2 & $2-3$ & $2-3$ \\
\hline Béjonniêres-i szilva & $6-7$ & 6 & 5 & 5 & 6 & 5 & 0 & 3 & $2-3$ & $2-3$ & $2-3$ \\
\hline Belga kék & $5-6$ & 5 & $5-6$ & 5 & $5-6$ & 5 & 0 & 1 & $1-2$ & 1 & $1-2$ \\
\hline Bellamira & 6 & $5-6$ & $5-6$ & $4-5$ & 5 & 5 & 0 & 3 & 2 & 2 & 2 \\
\hline Beni-detto & $5-6$ & $5-6$ & 6 & 5 & 5 & 5 & 0 & 3 & 2 & $1-2$ & 2 \\
\hline
\end{tabular}


Continuation of Table 1

\begin{tabular}{|c|c|c|c|c|c|c|c|c|c|c|c|}
\hline Species, cultivar & TB & WB & $\mathrm{RB}$ & NB & LB & $\mathrm{KB}$ & SB & $\mathrm{OP}$ & FR & SS & DR \\
\hline Berbencei szilva & 5 & 5 & 6 & 5 & 5 & $5-6$ & 0 & 2 & 1 & 2 & $1-2$ \\
\hline Beregi datolya & $5-6$ & $5-6$ & $5-6$ & 4 & 5 & 6 & 0 & 3 & 2 & 2 & 2 \\
\hline Bergthold korai mirabella & $5-6$ & $5-6$ & 5 & 5 & 5 & $5-6$ & 0 & 3 & $1-2$ & $1-2$ & 1 \\
\hline Bernardina & 6 & 5 & 5 & 5 & 5 & $5-6$ & 0 & 2 & 2 & 2 & 1 \\
\hline Besztercei Bb 398 & $5-6$ & 6 & $5-6$ & 5 & 5 & 6 & 0 & 2 & 1 & 2 & $1-2$ \\
\hline Besztercei Bb. 416 & $5-6$ & 6 & 6 & 6 & 5 & $5-6$ & 0 & 2 & 1 & 2 & 1 \\
\hline Besztercei Bt. 2 & 6 & $5-6$ & $5-6$ & $4-5$ & 5 & 6 & 0 & 2 & 1 & $1-2$ & 1 \\
\hline Besztercei C. 93 & 7 & 6 & 6 & 5 & $4-5$ & 6 & 0 & 3 & $1-2$ & 3 & 1 \\
\hline Besztercei Elvira 18 & 6 & $5-6$ & 5 & 5 & 5 & $5-6$ & $0-1$ & 2 & 1 & 2 & 1 \\
\hline Besztercei Kruft & $6-7$ & 6 & $5-6$ & 5 & 5 & 6 & 0 & 3 & 1 & $1-2$ & 1 \\
\hline Besztercei muskotály & $5-6$ & 5 & 5 & $4-5$ & 5 & $5-6$ & 0 & 1 & 1 & $2-3$ & $1-2$ \\
\hline Besztercei Nm. 116 & 6 & $5-6$ & 5 & 5 & $4-5$ & $5-6$ & 0 & 2 & 1 & 2 & 1 \\
\hline Besztercei Nm. 122 & $5-6$ & $5-6$ & $5-6$ & $4-5$ & 5 & 6 & 0 & 2 & 1 & 2 & 1 \\
\hline Besztercei Nm. 150 & $5-6$ & $5-6$ & $5-6$ & $4-5$ & 5 & 6 & 0 & 2 & 1 & $1-2$ & 1 \\
\hline Biodeck korai & 6 & 6 & 6 & 5 & 5 & 6 & 0 & 3 & 2 & 2 & $2-3$ \\
\hline Bistricka & 6 & 6 & $5-6$ & $5-5$ & 5 & $5-6$ & 0 & 2 & 1 & 2 & 1 \\
\hline Black Amber & 7 & 6 & 5 & $4-5$ & 6 & 6 & 0 & 3 & 3 & $1-2$ & 2 \\
\hline Black Beaut & $6-7$ & 6 & 6 & 5 & 6 & $6-7$ & 0 & 3 & $2-3$ & 2 & 2 \\
\hline Black Damas & 5 & 5 & 6 & 5 & 6 & 6 & 0 & $1-2$ & $1-2$ & 2 & 2 \\
\hline Black Diamond & $6-7$ & 6 & 6 & $4-5$ & 6 & $6-7$ & 0 & $2-3$ & 2 & $1-2$ & $2-3$ \\
\hline Black King & $6-7$ & 5 & $5-6$ & 5 & 7 & $6-7$ & 0 & $3-4$ & 3 & 2 & 2 \\
\hline Blaue Berliner Aprikosenpflaume & 6 & 6 & 6 & $5-6$ & 6 & 6 & 0 & 4 & $2-3$ & $1-2$ & 2 \\
\hline Bluefre & 6 & 5 & 5 & 5 & 6 & 6 & 0 & $2-3$ & 2 & 2 & 2 \\
\hline Bódi szilva & $5-6$ & $5-6$ & $5-6$ & 5 & 6 & $5-6$ & $0-1$ & $1-2$ & 1 & $1-2$ & $1-2$ \\
\hline Bohn mirabella & $5-6$ & 5 & 5 & 5 & 6 & $5-6$ & 0 & 2 & 2 & 2 & 1 \\
\hline Bon-bon & $5-6$ & 5 & $5-6$ & 5 & $5-6$ & 6 & 0 & 3 & 2 & $1-2$ & 2 \\
\hline Bonne de Bry & 6 & 5 & 5 & 5 & 6 & $5-6$ & 0 & 3 & 2 & 2 & 2 \\
\hline Bonnie 221 & $6-7$ & 6 & 6 & 5 & 6 & 7 & 0 & 3 & 2 & 2 & 3 \\
\hline Boranka & $5-6$ & 5 & $5-6$ & 5 & $5-6$ & $5-6$ & 0 & 2 & $1-2$ & 2 & 2 \\
\hline Bose piros szilva & $6-7$ & 6 & 5 & 5 & 6 & 6 & 0 & 3 & 2 & $2-3$ & $2-3$ \\
\hline Borsumi & $6-7$ & 5 & $5-6$ & $5-6$ & 6 & $5-6$ & 0 & 1 & 2 & 2 & $2-3$ \\
\hline Boszniai kék & $5-6$ & 5 & $5-6$ & 5 & 5 & $5-6$ & 0 & 2 & 1 & 3 & 1 \\
\hline Bosznia királynője & $5-6$ & 5 & 5 & $5-6$ & 5 & 5 & 0 & 3 & 1 & 2 & 2 \\
\hline Boszniai nagyherceg & $5-6$ & $5-6$ & 5 & 5 & 5 & $5-6$ & 0 & 2 & $1-2$ & 3 & 1 \\
\hline Bourdett Angelina & 5 & $4-5$ & $5-6$ & 5 & $5-6$ & 5 & 0 & 3 & $1-2$ & $1-2$ & 2 \\
\hline Brahy ringló & 6 & $5-6$ & 5 & $4-5$ & 6 & 5 & 0 & 3 & 2 & 2 & 3 \\
\hline Brassai & $5-6$ & $5-5$ & 5 & 5 & $5-6$ & 5 & 0 & 3 & 2 & 1 & $1-2$ \\
\hline Braunaui kajszinszilva & 6 & 5 & 6 & 5 & $5-6$ & 6 & 0 & 3 & 2 & $1-2$ & 2 \\
\hline Brianston ringló & $6-7$ & $5-6$ & 5 & 5 & 6 & 5 & 0 & 4 & 2 & 1 & 3 \\
\hline Brompton & 6 & $4-5$ & 6 & 4 & 6 & $6-7$ & 0 & 2 & 1 & $1-2$ & $1-2$ \\
\hline Brookred & $5-6$ & 5 & 6 & 5 & 6 & 6 & 0 & $2-3$ & 2 & $1-2$ & $2-3$ \\
\hline Brvamovska & 6 & $5-6$ & 6 & 5 & 6 & $5-6$ & 0 & $2-3$ & $1-2$ & 2 & 1 \\
\hline Buchner királyszilva & $5-6$ & $5-6$ & 5 & 5 & $5-6$ & 5 & 0 & 3 & $2-3$ & $2-3$ & $2-3$ \\
\hline Bucurie de Bucuresti & 6 & 6 & $5-6$ & 5 & 6 & $4-6$ & 0 & $2-3$ & $1-2$ & 2 & 2 \\
\hline Burbank & $6-7$ & 5 & $5-6$ & 5 & $5-6$ & 5 & $0-1$ & $3-4$ & 2 & 2 & 3 \\
\hline Burmosa & $6-7$ & 6 & $5-6$ & 5 & $5-6$ & $5-6$ & 0 & $2-3$ & 2 & 2 & 3 \\
\hline
\end{tabular}


Continuation of Table 1

\begin{tabular}{|c|c|c|c|c|c|c|c|c|c|c|c|}
\hline Species, cultivar & TB & WB & $\mathrm{RB}$ & NB & LB & $\mathrm{KB}$ & $\mathrm{SB}$ & $\mathrm{OP}$ & FR & SS & $\mathrm{DR}$ \\
\hline Burton & 6 & $5-6$ & $5-6$ & 5 & 5 & $5-6$ & 0 & 3 & $1-2$ & $1-2$ & 1 \\
\hline Busuioace de Gheurghiu & 6 & 5 & 6 & 5 & 5 & 6 & 0 & $2-3$ & $1-2$ & 2 & $1-2$ \\
\hline Bühle Verbote & $5-6$ & $5-6$ & $5-6$ & 5 & 5 & 5 & 0 & 2 & 1 & 2 & 2 \\
\hline Bühler Frühzwetsche & $5-6$ & 5 & 5 & $4-5$ & 6 & $5-6$ & 0 & $1-2$ & 1 & $1-2$ & $1-2$ \\
\hline Čačanska lepotica & 6 & $5-6$ & $5-6$ & 5 & $5-6$ & 5 & 0 & 1 & 2 & $1-2$ & 2 \\
\hline Čačanska najbolja & 6 & $5-6$ & $5-6$ & 5 & 5 & 5 & 0 & $1-2$ & $1-2$ & $1-2$ & $1-2$ \\
\hline Čačanska rana & 6 & $5-6$ & $5-6$ & 5 & $5-6$ & 5 & 0 & $2-3$ & 2 & 2 & $1-2$ \\
\hline Čačanska rodna & 6 & $5-6$ & $5-6$ & 5 & $5-6$ & 5 & 0 & $1-2$ & $1-2$ & 2 & $1-2$ \\
\hline Čačanska śečer & 6 & 5 & $5-6$ & 5 & 5 & 5 & 0 & 3 & $1-2$ & 2 & 2 \\
\hline California Blue & $5-6$ & $5-6$ & 5 & 4 & 5 & $5-6$ & 0 & 3 & $1-2$ & $1-2$ & 2 \\
\hline Cambridge Gage & 6 & 6 & 6 & 5 & 5 & 5 & 0 & 2 & 2 & 2 & 2 \\
\hline Casalinga & $5-6$ & 5 & $5-6$ & $4-5$ & 5 & 6 & 0 & $2-3$ & 1 & $2-3$ & 1 \\
\hline Centenar & $5-6$ & 6 & 6 & 5 & 5 & 5 & 0 & 3 & 2 & $1-2$ & 2 \\
\hline Chalonsi kései & $5-6$ & $5-6$ & $5-6$ & $4-5$ & 5 & 5 & 0 & 3 & 2 & $2-3$ & $2-3$ \\
\hline Charcuty & $6-7$ & 6 & 6 & 5 & 5 & $5-6$ & $0-1$ & 4 & 3 & 3 & 3 \\
\hline Chrudimer & $5-6$ & $5-6$ & $5-6$ & 5 & $5-6$ & 5 & 0 & 2 & $1-2$ & $1-2$ & $1-2$ \\
\hline Cieza No. 1 & 5 & 5 & 5 & 5 & 5 & $5-6$ & 0 & 2 & $1-2$ & 2 & 1 \\
\hline Coates & 6 & $5-6$ & 5 & 5 & $5-6$ & 6 & 0 & $2-3$ & 2 & 2 & 2 \\
\hline Cochet & $6-7$ & 6 & 6 & 5 & $5-6$ & $5-6$ & 0 & $2-3$ & $2-3$ & 2 & $2-3$ \\
\hline Coë’s Golden Drop & $5-6$ & 5 & $4-5$ & 5 & 5 & 5 & 0 & 2 & $1-2$ & 1 & $1-2$ \\
\hline Columbia & 6 & $5-6$ & 5 & 5 & $5-6$ & $5-6$ & 0 & 3 & $2-3$ & 3 & 1 \\
\hline Compass & 5 & 5 & 6 & $4-5$ & 6 & 7 & 0 & $1-2$ & 2 & 2 & 3 \\
\hline Cooper nagy szilvája & 6 & 6 & 6 & 5 & 6 & $5-6$ & 0 & 2 & 2 & 2 & 3 \\
\hline Crimson Drop & 6 & 5 & 5 & 5 & $5-6$ & 6 & 0 & $2-3$ & 2 & $2-3$ & 2 \\
\hline Czar & $5-6$ & $5-6$ & $5-6$ & 6 & 5 & 6 & 0 & 1 & $1-2$ & 2 & 2 \\
\hline Czernowitzer & $5-6$ & $5-6$ & 5 & 5 & $5-6$ & $5-6$ & 0 & $2-3$ & 2 & 1 & 2 \\
\hline Csahticska & 6 & 6 & 6 & 5 & $5-6$ & 6 & 0 & 3 & $1-2$ & 2 & 2 \\
\hline Cservena Afazka & $6-7$ & 6 & 6 & 6 & $5-6$ & 6 & 0 & $1-2$ & $1-2$ & 1 & $1-2$ \\
\hline Csúcsos szilva & $5-6$ & 5 & $5-6$ & $5-6$ & 5 & 6 & 0 & 4 & 2 & 2 & 2 \\
\hline D'Alsace & 6 & $5-6$ & 5 & 5 & 5 & $5-6$ & 0 & 2 & $1-2$ & $2-3$ & 1 \\
\hline Dames de Tours & $5-6$ & $5-6$ & $5-6$ & 6 & $5-6$ & 6 & 0 & 3 & 2 & 2 & 2 \\
\hline De Maris & 6 & 6 & 6 & $5-6$ & $5-6$ & 6 & 0 & $3-4$ & 3 & 2 & $2-3$ \\
\hline De Soto & 6 & 5 & $5-6$ & 4 & $6-7$ & 7 & 0 & $3-4$ & 3 & 1 & $1-2$ \\
\hline Debreceni muskotály & 6 & 6 & $5-6$ & $5-6$ & 5 & 6 & 0 & $2-3$ & $1-2$ & $1-2$ & 2 \\
\hline Decaisne szilva & 6 & $5-6$ & 6 & 6 & $5-6$ & 6 & 0 & 2 & $2-3$ & 2 & 2 \\
\hline Déli Vengerka & 6 & 6 & $5-6$ & 5 & 6 & 6 & 0 & $2-3$ & 1 & 2 & 1 \\
\hline Denniston piros szilva & $5-6$ & $5-6$ & 6 & $5-6$ & 6 & 6 & 0 & 1 & 2 & $1-2$ & $2-3$ \\
\hline Denniston's Superb & 6 & 6 & 5 & $5-6$ & $5-6$ & 6 & 0 & 1 & 2 & 2 & 3 \\
\hline Dewett & $5-6$ & $5-6$ & $5-6$ & $5-6$ & 5 & $5-6$ & 0 & 3 & $2-3$ & 2 & 2 \\
\hline Diamond & $6-7$ & 6 & 6 & 5 & $6-7$ & 6 & 0 & 3 & $2-3$ & 2 & 2 \\
\hline Dombrovița & $5-6$ & 6 & 6 & $5-6$ & $5-6$ & 6 & 0 & 3 & 2 & 2 & 2 \\
\hline Dörell nagy szilva & 6 & 6 & $5-6$ & 5 & $5-6$ & 6 & 0 & 3 & $1-2$ & 2 & 2 \\
\hline Drjanovoi & $5-6$ & $5-6$ & $6-7$ & $5-6$ & $5-6$ & 6 & 0 & 2 & $1-2$ & $2-3$ & 1 \\
\hline Duke Edinbough & $5-6$ & $5-6$ & $6-6$ & 5 & $5-6$ & 6 & 0 & 3 & $2-3$ & 2 & 2 \\
\hline Duarte & $6-7$ & $5-6$ & 6 & $4-5$ & $6-7$ & $6-7$ & 0 & 3 & 2 & 2 & 2 \\
\hline Duránci szilva & 6 & $6-7$ & $5-6$ & 5 & $5-6$ & $5-6$ & 0 & 2 & $1-2$ & 1 & 1 \\
\hline
\end{tabular}


Continuation of Table 1

\begin{tabular}{|c|c|c|c|c|c|c|c|c|c|c|c|}
\hline Species, cultivar & $\mathrm{TB}$ & WB & $\mathrm{RB}$ & NB & LB & $\mathrm{KB}$ & SB & $\mathrm{OP}$ & FR & SS & DR \\
\hline Duránci szilva C. 1512 & 6 & 6 & 5 & 5 & 5 & 6 & $0-1$ & 2 & $1-2$ & 1 & 1 \\
\hline Dzsanka 1 & $6-7$ & $4-5$ & $5-6$ & 4 & 6 & 7 & 0 & 1 & $1-2$ & $1-2$ & 1 \\
\hline Dzsanka $1 / 4$ & $6-7$ & 5 & $5-6$ & $4-5$ & $5-6$ & $6-7$ & $0-1$ & 1 & 1 & $1-2$ & 1 \\
\hline Dzsanka 3 & $6-7$ & 5 & $5-6$ & $4-5$ & $5-6$ & $6-7$ & $0-1$ & 1 & $1-2$ & 2 & 1 \\
\hline Early Favorite & 6 & 6 & $5-6$ & $5-6$ & 6 & 6 & 0 & $3-4$ & 2 & 2 & $1-2$ \\
\hline Early Laxtons & $5-6$ & $5-6$ & $5-6$ & 6 & $5-6$ & 6 & 0 & $3-4$ & 2 & 2 & 2 \\
\hline Early Mirabelle & $5-6$ & $5-6$ & 6 & 5 & $5-6$ & 6 & 0 & 2 & 2 & 1 & 2 \\
\hline Early Rivers & 6 & 6 & $5-6$ & $5-6$ & 6 & 6 & 0 & 4 & $1-2$ & 2 & $1-2$ \\
\hline Ebersweier Frühzwetsche & 5 & $5-6$ & 6 & $5-6$ & 6 & $5-6$ & 0 & 4 & $1-2$ & 2 & $1-2$ \\
\hline Egger Gusztáv & 6 & 6 & 6 & $5-6$ & $5-6$ & 6 & 0 & 2 & 2 & 2 & $1-2$ \\
\hline Eldorado & 7 & 6 & 6 & 5 & $6-7$ & 7 & 0 & 3 & $2-3$ & $2-3$ & 2 \\
\hline Elena & $5-6$ & 5 & 5 & $5-6$ & $5-6$ & $5-6$ & 0 & 2 & 2 & 2 & 2 \\
\hline Elephant Heart & 7 & $5-6$ & 5 & $4-5$ & 5 & 6 & 0 & $2-3$ & $2-3$ & 2 & $1-2$ \\
\hline Ember & $5-6$ & 6 & $5-6$ & 5 & 6 & 6 & 0 & 3 & 2 & 2 & 1 \\
\hline Empress & 6 & 6 & 5 & 5 & 6 & 6 & 0 & 3 & $1-2$ & $1-2$ & 2 \\
\hline Englebert herceg & $5-6$ & $5-6$ & $5-6$ & 5 & $5-6$ & $5-6$ & 0 & $2-3$ & $1-2$ & 2 & $1-2$ \\
\hline Ersinger Frühzwetsche & $5-6$ & 5 & $5-6$ & $5-6$ & 5 & 6 & 0 & $2-3$ & $1-2$ & 2 & $1-2$ \\
\hline Erdei nyakas & $5-6$ & $5-6$ & $5-6$ & 5 & 6 & 6 & 0 & 3 & 2 & $1-2$ & 2 \\
\hline Esperen aranyszilvája & 6 & 6 & 6 & $5-6$ & $5-6$ & $5-6$ & 0 & 3 & $2-3$ & 2 & $1-2$ \\
\hline Esslinger Frühzwetsche & $5-6$ & $5-6$ & $5-6$ & $5-5$ & 5 & $5-6$ & 0 & 2 & 2 & 2 & 2 \\
\hline Fazekas duránci & 6 & 6 & $5-6$ & 5 & $5-6$ & 6 & 0 & $2-3$ & $1-2$ & 1 & $1-2$ \\
\hline Fehér császárnő & $5-6$ & $5-6$ & 6 & 6 & $5-6$ & 6 & 0 & 3 & 2 & 2 & 2 \\
\hline Fehér diapré & 6 & 6 & $5-6$ & 6 & 6 & $5-6$ & 0 & 3 & $1-2$ & 2 & 2 \\
\hline Fehér királynő & 6 & $5-6$ & 6 & $5-6$ & $5-6$ & 6 & 0 & 3 & 2 & $2-3$ & 2 \\
\hline Fehér szilva & 5 & 5 & $5-6$ & $5-6$ & $5-6$ & 6 & $0-1$ & $1-2$ & $1-2$ & 2 & $1-2$ \\
\hline Fellenberg & 5 & 6 & 6 & 5 & 6 & $5-6$ & 0 & 3 & $1-2$ & 3 & 2 \\
\hline Firbas királyszilva & 6 & 6 & 6 & $5-6$ & $5-6$ & $5-6$ & 0 & $2-3$ & 2 & 2 & 2 \\
\hline Flotow mirabella & $5-6$ & 5 & 5 & 5 & $5-6$ & 6 & 0 & 1 & 1 & $1-2$ & 3 \\
\hline Formosa & $6-7$ & 6 & 6 & 6 & $6-7$ & 6 & 0 & 3 & 3 & 2 & 2 \\
\hline Francia narancs szilva & 6 & 6 & 6 & $5-6$ & 6 & 6 & 0 & 3 & 3 & 3 & 2 \\
\hline Frankfurti kék & $5-6$ & $5-6$ & $5-6$ & $5-6$ & 6 & $5-6$ & 0 & $2-3$ & $1-2$ & $2-3$ & 3 \\
\hline Freudenbergi korai & 6 & $5-6$ & 5 & 5 & 6 & $5-6$ & 0 & $2-3$ & 2 & 2 & 2 \\
\hline Friar & 7 & 5 & 5 & 5 & $5-6$ & $5-6$ & 0 & 3 & $2-3$ & 2 & $1-2$ \\
\hline Frontier & 7 & 5 & 5 & 5 & $5-6$ & 6 & 0 & $2-3$ & $2-3$ & 2 & 2 \\
\hline Fultoni sárga & 5 & 5 & 5 & 5 & $5-6$ & 6 & 0 & 4 & $2-3$ & 3 & 2 \\
\hline Gabrovszka & 6 & 6 & $5-6$ & 5 & 6 & $5-6$ & 0 & 3 & $1-2$ & 2 & 2 \\
\hline Gajdelli szilva & $5-6$ & $5-6$ & 6 & $5-6$ & 6 & $5-6$ & 0 & $1-2$ & 1 & $2-3$ & 1 \\
\hline Gaviota & 6 & $5-6$ & 6 & $4-5$ & $6-7$ & $6-7$ & 0 & 3 & 2 & 2 & 2 \\
\hline Giant & 6 & 6 & 5 & 5 & 6 & 6 & 0 & $2-3$ & 2 & 2 & $1-2$ \\
\hline Giant Super & $6-7$ & 5 & $5-6$ & 5 & 7 & $6-7$ & 0 & 3 & $2-3$ & $1-2$ & 2 \\
\hline Gilbert & $5-6$ & $5-6$ & 5 & 5 & 6 & 6 & 0 & $1-2$ & $1-2$ & 2 & 1 \\
\hline Ginsborne szilva & $5-6$ & 6 & $5-6$ & $5-6$ & $5-6$ & 6 & 0 & $2-3$ & 2 & $2-3$ & 2 \\
\hline Gloria & $6-7$ & 6 & 6 & $5-6$ & 6 & 6 & 0 & $2-3$ & 2 & 2 & 2 \\
\hline Goff & $6-7$ & $5-6$ & 6 & 5 & $6-7$ & 7 & 0 & 3 & $2-3$ & 2 & 2 \\
\hline Golden Beauty & $6-7$ & 5 & 6 & 4 & 6 & $6-7$ & 0 & 3 & 3 & $2-3$ & $2-3$ \\
\hline Golden Drop & $6-7$ & 6 & 6 & 5 & 6 & 6 & 0 & $3-4$ & $2-3$ & $2-3$ & 1 \\
\hline
\end{tabular}


Continuation of Table 1

\begin{tabular}{|c|c|c|c|c|c|c|c|c|c|c|c|}
\hline Species, cultivar & $\mathrm{TB}$ & WB & $\mathrm{RB}$ & $\mathrm{NB}$ & LB & $\mathrm{KB}$ & SB & OP & FR & SS & DR \\
\hline Golden King & $6-7$ & 6 & 6 & $4-5$ & $6-7$ & 7 & 0 & $3-4$ & 2 & $2-3$ & 2 \\
\hline Golden Sugar & $5-6$ & 6 & 6 & $5-6$ & 6 & 6 & 0 & $2-4$ & $2-3$ & 2 & 2 \\
\hline Gondini & $5-6$ & $5-6$ & $5-6$ & 6 & 6 & 6 & 0 & 2 & 2 & 2 & 3 \\
\hline Gömöri nyakas & $5-6$ & $6-7$ & $5-6$ & $5-6$ & $6-7$ & $5-6$ & 0 & 3 & 2 & $2-3$ & 2 \\
\hline Grand Prize & $5-6$ & $6-7$ & 5 & 5 & 6 & 6 & 0 & 3 & $2-3$ & $2-3$ & 2 \\
\hline Gras ameliorat & 5 & 6 & $5-6$ & 5 & $5-6$ & $5-6$ & 0 & 3 & $1-2$ & 2 & $1-2$ \\
\hline Gras Dames & $5-6$ & 6 & $5-6$ & $5-6$ & 6 & 6 & 0 & $3-4$ & $1-2$ & 2 & 2 \\
\hline Graves Late Victoria & 6 & $5-6$ & $5-6$ & 6 & $5-6$ & 6 & 0 & 3 & 2 & $1-2$ & 2 \\
\hline Grosse Mirabelle & $5-6$ & 6 & 5 & $5-6$ & $5-6$ & 6 & 0 & 3 & 2 & $1-2$ & 2 \\
\hline Gulieva & 6 & $5-6$ & $5-6$ & $5-6$ & 6 & $5-6$ & 0 & 3 & 1 & 2 & 2 \\
\hline H. 59 & 5 & $5-6$ & 5 & $5-6$ & $5-6$ & $5-6$ & 0 & 3 & 2 & $1-2$ & 2 \\
\hline H. 307 & $5-6$ & $5-6$ & $5-6$ & 5 & 5 & 6 & 0 & $2-3$ & 2 & 2 & 2 \\
\hline H. 331 & $5-6$ & 6 & $5-6$ & $5-6$ & $5-6$ & $5-6$ & 0 & $2-3$ & 2 & $1-2$ & 2 \\
\hline Н. 367 & 5 & $5-6$ & 5 & 5 & $5-6$ & $5-6$ & 0 & $1-2$ & $2-3$ & 2 & 2 \\
\hline H. 480 & $5-6$ & 6 & $5-6$ & 5 & $5-6$ & $5-6$ & 0 & 2 & 1 & 2 & 2 \\
\hline H. 647 & 6 & $5-6$ & 5 & $5-6$ & 5 & 5 & 0 & 2 & $1-2$ & 1 & 2 \\
\hline H. 700 & $5-6$ & 6 & 5 & 5 & $5-6$ & $5-6$ & 0 & $2-3$ & 1 & 2 & 2 \\
\hline H. 1444 & 6 & $5-6$ & 5 & $5-6$ & 5 & 5 & 0 & 2 & 2 & 2 & 2 \\
\hline Haffner őszi & 6 & 6 & $5-6$ & $5-6$ & 6 & 6 & 0 & 2 & 1 & 3 & 3 \\
\hline Haganta & $5-6$ & $5-6$ & $5-6$ & 5 & $5-6$ & $5-6$ & 0 & 2 & 2 & 2 & 2 \\
\hline Hall & 6 & $6-7$ & $5-6$ & 5 & 5 & $5-6$ & 0 & 2 & 2 & 2 & 1 \\
\hline Hanita & $5-6$ & $5-6$ & 5 & 5 & 5 & $5-6$ & 0 & $1-2$ & $1-2$ & 2 & $1-2$ \\
\hline Hanka & $5-6$ & 6 & $5-6$ & $5-6$ & 5 & $5-6$ & 0 & $1-2$ & 2 & $1-2$ & 2 \\
\hline Haroma & 6 & $5-6$ & $5-6$ & $5-6$ & 5 & 6 & 0 & $1-2$ & $1-2$ & $1-2$ & 2 \\
\hline Hartwiss sárga & 5 & $5-6$ & $5-6$ & 5 & 6 & 6 & 0 & $2-3$ & $1-2$ & 2 & $1-2$ \\
\hline Hegyes szilva & $5-6$ & $5-6$ & 5 & 5 & $5-6$ & 6 & 0 & 3 & 1 & 2 & 2 \\
\hline Henry Courcelles & 6 & $5-6$ & 5 & $5-6$ & $5-6$ & 6 & $0-1$ & 3 & $1-2$ & 2 & 2 \\
\hline Herman & 6 & 6 & 5 & 5 & 5 & $5-6$ & 0 & 4 & 2 & $1-2$ & 2 \\
\hline Herrnhausi nagy mirabella & $5-6$ & $5-6$ & 5 & $5-6$ & 5 & 6 & 0 & $1-2$ & 2 & $1-2$ & $1-2$ \\
\hline Hlubeck kajszinszilva & 6 & $5-6$ & 5 & 6 & $5-6$ & $6-7$ & 0 & $3-4$ & $2-3$ & $1-2$ & 2 \\
\hline Hohenheim 1 & $5-6$ & 5 & $5-6$ & $5-6$ & 5 & 6 & 0 & 3 & $1-2$ & 2 & $2-3$ \\
\hline Hohenheim 2 & $5-6$ & $5-6$ & 5 & $5-6$ & $5-6$ & 6 & 0 & 3 & 2 & 2 & 2 \\
\hline Hohenheim 3 & $5-6$ & $5-6$ & $5-6$ & 5 & 5 & $5-6$ & 0 & 3 & 2 & $2-3$ & $2-3$ \\
\hline Hohenheim 4 & 6 & 6 & $5-6$ & $5-6$ & $5-6$ & 6 & 0 & 2 & 1 & $1-2$ & $1-2$ \\
\hline Hohenheim 5 & $5-6$ & 6 & $5-6$ & $5-6$ & $5-6$ & $5-6$ & 0 & $3-4$ & 2 & 2 & 2 \\
\hline Hollandi szilva C. 940 & $5-6$ & 6 & 6 & $5-6$ & 6 & $5-6$ & 0 & $2-3$ & 1 & 2 & 2 \\
\hline Honey Moon & 6 & $5-6$ & 5 & $5-6$ & 6 & 6 & 0 & $2-3$ & 1 & 2 & 2 \\
\hline Hosszú kék damaszkuszi & 6 & 5 & 5 & $4-5$ & 5 & 6 & $0-1$ & 2 & $1-2$ & $2-3$ & 1 \\
\hline I. Ferenc József & $5-6$ & $5-6$ & $5-6$ & 5 & $5-6$ & 6 & 0 & 3 & 2 & 2 & 2 \\
\hline Idillija & 6 & 6 & 6 & $5-6$ & 6 & $6-7$ & $0-1$ & 3 & 1 & $2-3$ & 2 \\
\hline $\mathrm{II} / \mathrm{b} .21 / 1$ & $5-6$ & $5-6$ & $5-6$ & 5 & 5 & $5-6$ & 0 & 2 & $1-2$ & 2 & 2 \\
\hline Imperial Bulgar & $5-6$ & $5-6$ & $5-6$ & $5-6$ & 6 & 6 & 0 & 4 & $1-2$ & 2 & $1-2$ \\
\hline Imperial Epineuse & 5 & $5-6$ & $5-6$ & 5 & 6 & 6 & 0 & 3 & 2 & 2 & 1 \\
\hline Italian Prune & 6 & 6 & 6 & $5-6$ & 6 & 6 & 0 & 3 & 2 & $2-3$ & 2 \\
\hline Izabella & $5-6$ & 5 & $5-6$ & $5-6$ & $5-6$ & 6 & 0 & 4 & $2-3$ & $2-3$ & $1-2$ \\
\hline Japanese Gold & $6-7$ & 5 & 6 & 5 & $6-7$ & $6-7$ & 0 & 4 & 2 & $2-3$ & 2 \\
\hline
\end{tabular}


Continuation of Table 1

\begin{tabular}{|c|c|c|c|c|c|c|c|c|c|c|c|}
\hline Species, cultivar & TB & WB & $\mathrm{RB}$ & NB & LB & $\mathrm{KB}$ & SB & OP & FR & SS & DR \\
\hline Javított Olasz kék & $5-6$ & $6-7$ & 6 & $5-6$ & 6 & 6 & 0 & 3 & 2 & 2 & 2 \\
\hline Jefferson' Gage & 5 & 6 & 5 & 5 & $5-6$ & 5 & 0 & 2 & 1 & 2 & 2 \\
\hline Jelica & $5-6$ & $5-6$ & 5 & $4-5$ & 5 & 6 & 0 & $2-3$ & 1 & 1 & 2 \\
\hline Jeruzsámei kék & 5 & $5-6$ & $5-6$ & $4-5$ & $5-6$ & $5-6$ & 0 & 3 & 1 & 1 & 2 \\
\hline Jodoigne ringló & 6 & 6 & $5-6$ & 5 & $5-6$ & $5-6$ & 0 & 3 & 2 & 2 & $1-2$ \\
\hline Jojo & 5 & $5-6$ & 5 & 5 & $5-6$ & $5-6$ & 0 & $1-2$ & $1-2$ & 0 & $1-2$ \\
\hline Jori's Pflaume & 6 & $5-6$ & $5-6$ & $5-6$ & 6 & $5-6$ & 0 & $2-3$ & $1-2$ & $1-2$ & 2 \\
\hline Jubileumi kék & 6 & 6 & $5-6$ & 5 & 6 & 6 & 0 & $2-3$ & 2 & 2 & 2 \\
\hline Júliusi zöld ringló & $5-6$ & 6 & $5-6$ & 5 & $5-6$ & 6 & 0 & $3-4$ & 2 & $1-2$ & $1-2$ \\
\hline July Santa Rosa & $6-7$ & $5-6$ & 5 & $4-5$ & 5 & 7 & 0 & 3 & $1-2$ & 2 & 2 \\
\hline Karasu & $6-7$ & 6 & 6 & $5-6$ & 6 & $5-6$ & $0-1$ & 2 & 1 & 2 & $1-2$ \\
\hline Katalán & 5 & 5 & 5 & $5-6$ & 5 & 6 & 0 & $1-2$ & 1 & $1-2$ & $1-2$ \\
\hline Katinka & $5-6$ & $5-6$ & 5 & 5 & $5-6$ & 6 & 0 & $1-2$ & 1 & 2 & $1-2$ \\
\hline Kazak szilva & 6 & 6 & 5 & $5-6$ & $5-6$ & 6 & $0-1$ & 2 & 2 & 2 & 2 \\
\hline Kecskeméti 101 & 6 & 6 & $5-6$ & $5-6$ & 6 & 6 & 0 & 3 & 2 & 1 & 2 \\
\hline Kék datolya & 6 & 6 & 6 & $5-6$ & $5-6$ & $5-6$ & 0 & 4 & 2 & $1-2$ & $2-3$ \\
\hline Kék diapré & $5-6$ & 6 & 5 & $5-6$ & $5-6$ & 6 & 0 & 3 & 2 & 2 & 2 \\
\hline Kék tojás & 6 & 6 & $5-6$ & $5-6$ & 6 & 6 & 0 & $3-4$ & 2 & $1-2$ & $1-2$ \\
\hline Kései mirabella & 5 & $5-6$ & $5-6$ & $5-6$ & 6 & 6 & 0 & 3 & 1 & $1-2$ & 2 \\
\hline Kései muskotály & 5 & 5 & 5 & $5-6$ & 6 & 6 & 0 & 4 & $1-2$ & 2 & $1-2$ \\
\hline King of Damson & $5-6$ & $5-6$ & $5-6$ & 5 & $5-6$ & $5-6$ & 0 & 2 & $1-2$ & $2-3$ & 2 \\
\hline Kirke szilvája & $5-6$ & 5 & $5-6$ & 5 & 6 & 6 & 0 & 3 & $1-2$ & 1 & 1 \\
\hline Kisinyevszkij rannij & 6 & 6 & $5-6$ & $5-6$ & $5-6$ & $5-6$ & 0 & $1-2$ & 1 & 1 & $1-2$ \\
\hline Kissinger Rose & $6-7$ & 6 & 6 & $5-6$ & $5-6$ & 6 & 0 & 2 & $2-3$ & $2-3$ & 2 \\
\hline Kometa & $5-6$ & $5-6$ & 6 & $5-6$ & $5-6$ & 6 & $0-1$ & $3-4$ & 2 & 2 & 1 \\
\hline Korai Besztercei & 6 & 5 & 5 & 5 & 5 & $5-6$ & 0 & 3 & 1 & 3 & $1-2$ \\
\hline Korai Besztercei Cs. 1 & 6 & 5 & $5-6$ & 5 & 5 & $5-6$ & 0 & 2 & 1 & $2-3$ & 2 \\
\hline Korai Besztercei Cs. 2 & 6 & 5 & $5-6$ & 5 & 5 & 6 & 0 & 2 & 1 & $2-3$ & 2 \\
\hline Korai kajszinszilva & 6 & $5-6$ & 5 & $5-6$ & $5-6$ & 6 & 0 & $3-4$ & $2-3$ & 2 & 2 \\
\hline Korai kedvenc & $5-6$ & $5-6$ & $5-6$ & 5 & 5 & $5-6$ & 0 & 2 & $1-2$ & 2 & $1-2$ \\
\hline Korai nemes szilva & 6 & 6 & 5 & 5 & $5-6$ & $5-6$ & 0 & 3 & 2 & $2-3$ & 2 \\
\hline Korai termékeny & $5-6$ & 6 & 6 & $5-6$ & 6 & $5-6$ & 0 & 2 & 2 & 2 & 1 \\
\hline Korai zöld & 5 & 5 & $5-6$ & 5 & $5-6$ & 6 & 0 & 3 & 3 & 2 & 1 \\
\hline Kökényszilva & $5-6$ & $5-6$ & 6 & $5-6$ & 6 & 6 & 0 & 2 & 1 & $1-2$ & 2 \\
\hline Kökényszilva CT. 93 & $5-6$ & 6 & 6 & $5-6$ & $5-6$ & 6 & 0 & $1-2$ & $1-2$ & $2-3$ & 2 \\
\hline KönigsbergI & 5 & $5-6$ & $5-6$ & 5 & 5 & $5-6$ & 0 & 3 & $1-2$ & 2 & 2 \\
\hline Königspflaume & $5-6$ & $5-6$ & 6 & $5-6$ & $5-6$ & $5-6$ & 0 & 3 & $1-2$ & $2-3$ & $2-3$ \\
\hline Krina & $6-7$ & $5-6$ & $6-7$ & 6 & 6 & 6 & 0 & 3 & 2 & 2 & 2 \\
\hline KSZ-4 & $6-7$ & 6 & 6 & 6 & $5-6$ & 6 & $0-1$ & $3-4$ & $2-3$ & $2-3$ & 2 \\
\hline KSZ-9 & $6-7$ & 6 & 6 & 6 & 6 & 6 & $0-1$ & $3-4$ & 2 & 2 & 2 \\
\hline KSZ-31 & $6-7$ & 6 & 6 & 6 & $5-6$ & 6 & $0-1$ & $3-4$ & $2-3$ & $2-3$ & 2 \\
\hline Küsztendili & 6 & $5-6$ & $6-7$ & 6 & $5-6$ & 6 & 0 & $2-3$ & 1 & 3 & $1-2$ \\
\hline Lafayette & 6 & 6 & $5-6$ & $5-6$ & $5-6$ & $5-6$ & 0 & 4 & 2 & 2 & 2 \\
\hline Laroda & $6-7$ & 5 & $5-6$ & 4 & $6-7$ & 7 & 0 & 3 & 2 & 3 & 3 \\
\hline Late Orange & $6-7$ & 6 & 6 & $5-6$ & 6 & 6 & 0 & 4 & 3 & $2-3$ & $2-3$ \\
\hline Late Santa Rosa & $6-7$ & $5-6$ & $5-6$ & $4-5$ & 5 & $6-7$ & 0 & 3 & 2 & 2 & 1 \\
\hline
\end{tabular}


Continuation of Table 1

\begin{tabular}{|c|c|c|c|c|c|c|c|c|c|c|c|}
\hline Species, cultivar & $\mathrm{TB}$ & WB & $\mathrm{RB}$ & NB & LB & KB & SB & OP & FR & SS & DR \\
\hline Late Tragedy & $5-6$ & 5 & 5 & $5-6$ & $5-6$ & 6 & 0 & $2-3$ & $1-2$ & $1-2$ & 2 \\
\hline Laubinger & $5-6$ & $5-6$ & 6 & $5-6$ & 6 & $5-6$ & 0 & 4 & 3 & 2 & 2 \\
\hline Lawrence ringló & 6 & 6 & $5-6$ & $5-6$ & 6 & $5-6$ & 0 & 3 & $2-3$ & $2-3$ & 2 \\
\hline Lawson sárga & 6 & 6 & 6 & $5-6$ & $5-6$ & $5-6$ & 0 & 3 & 2 & 2 & $2-3$ \\
\hline Laxton's Blue & 5 & 5 & $5-6$ & 5 & 6 & 6 & 0 & 3 & 2 & 2 & 2 \\
\hline Laxton,'s Gage & 6 & 6 & 6 & $5-6$ & 6 & 6 & 0 & 3 & 2 & 2 & 2 \\
\hline Lemon plum & 7 & $6-7$ & 6 & $5-6$ & $6-7$ & $6-7$ & $0-1$ & 4 & 3 & $1-2$ & 2 \\
\hline Lengyel szilva & $5-6$ & $6-7$ & $5-6$ & $5-6$ & 5 & 6 & 0 & 2 & 1 & $2-3$ & $2-3$ \\
\hline Lepine & 6 & 6 & $5-6$ & 5 & $5-6$ & 6 & 0 & 2 & 2 & 2 & $1-2$ \\
\hline Leppermann Emma & $5-6$ & 6 & 6 & $5-6$ & 5 & 6 & 0 & $2-3$ & 1 & $1-2$ & 2 \\
\hline Letricourt & 6 & $5-6$ & $5-6$ & 5 & 5 & 6 & 0 & 3 & 2 & 2 & 1 \\
\hline Liegel iker & 6 & 6 & 6 & $5-6$ & $5-6$ & 6 & 0 & $2-3$ & 2 & 2 & $2-3$ \\
\hline Lincoln & $5-6$ & $5-6$ & 5 & $5-6$ & $5-6$ & 6 & 0 & 2 & $2-3$ & 3 & 1 \\
\hline Lombard szilva & $6-7$ & 6 & $5-6$ & 5 & 5 & $5-6$ & 0 & $2-3$ & 2 & 2 & 2 \\
\hline Lószemű szilva & $5-6$ & 5 & $5-6$ & $4-5$ & 5 & 6 & 0 & 3 & 1 & 2 & 1 \\
\hline Lószemű szilva C. 1502 & $5-6$ & $5-6$ & $5-6$ & 5 & $5-6$ & 6 & $0-1$ & 3 & 1 & 1 & 1 \\
\hline Löhrpflaume & $5-6$ & $5-6$ & 5 & $5-6$ & 5 & 6 & 0 & $2-3$ & 2 & $1-2$ & $1-2$ \\
\hline Lőweni szép & 5 & $6-7$ & 5 & $5-6$ & $5-6$ & 6 & 0 & 3 & 2 & $1-2$ & 2 \\
\hline Lucas királyszilva & 6 & 6 & 6 & 6 & 5 & 6 & 0 & $1-2$ & $2-3$ & $1-2$ & 3 \\
\hline Lützersacher Frühzwetsche & $5-6$ & $5-6$ & $5-6$ & 5 & $5-6$ & 6 & 0 & $2-3$ & 2 & 2 & 2 \\
\hline MacLaughlin & 5 & $5-6$ & $5-6$ & 5 & $5-6$ & $6-7$ & 0 & 2 & 2 & 3 & 2 \\
\hline Magna Glauca & $5-6$ & 6 & $5-6$ & 5 & 5 & 6 & 0 & $3-4$ & $1-2$ & $1-2$ & $1-2$ \\
\hline Magyar datolyaszilva & $5-6$ & $5-6$ & $5-6$ & 5 & 5 & 6 & 0 & $3-4$ & 3 & 2 & 2 \\
\hline Mainzi korai & 5 & 5 & 6 & 5 & $5-6$ & 6 & 0 & 3 & $2-3$ & 2 & 2 \\
\hline Máramarosi nyakas & 5 & 6 & 5 & $5-6$ & 6 & $5-6$ & 0 & $3-4$ & 2 & $1-2$ & 2 \\
\hline Marianna W. 39 & $5-6$ & 5 & 6 & 5 & 6 & 7 & 0 & $1-2$ & $1-2$ & 2 & 2 \\
\hline Mariposa & $6-7$ & $5-6$ & 6 & $4-5$ & $6-7$ & 7 & 0 & 2 & 2 & 2 & $1-2$ \\
\hline Markuja & $5-6$ & 5 & 5 & 4 & 5 & $6-7$ & $0-1$ & 4 & 1 & 2 & 2 \\
\hline Mas császárszilva & 5 & $5-6$ & $5-6$ & 5 & $5-6$ & 6 & 0 & $2-3$ & $2-3$ & 2 & 3 \\
\hline Mascina de Montepulciano & 6 & 6 & 6 & $5-6$ & 6 & $6-7$ & 0 & $2-3$ & 2 & $2-3$ & 2 \\
\hline Maugeroni szilva & 6 & $5-6$ & 6 & 6 & 6 & $6-7$ & 0 & 4 & $1-2$ & 2 & 2 \\
\hline Meroldt ringló & $5-6$ & 6 & $5-6$ & 5 & $5-6$ & $5-6$ & 0 & 3 & 2 & 2 & 2 \\
\hline Merryweather & 7 & 6 & $5-6$ & $5-6$ & $5-6$ & 6 & 0 & 1 & $2-3$ & $2-3$ & 3 \\
\hline Methley & 7 & $5-6$ & 5 & 5 & 5 & 5 & 0 & 2 & 2 & $1-2$ & 2 \\
\hline Metzi mirabella & $5-6$ & 5 & 5 & 5 & 5 & 6 & 0 & $2-3$ & 2 & 1 & $1-2$ \\
\hline Milánói császár & $6-7$ & 6 & $5-6$ & 5 & $5-6$ & $5-6$ & 0 & 4 & $2-3$ & $2-3$ & 2 \\
\hline Mildora & 6 & 6 & 6 & 5 & 6 & 5 & 0 & $3-4$ & 2 & 2 & 2 \\
\hline Mirabellák királynője & $5-6$ & 5 & $5-6$ & 5 & 6 & 6 & 0 & 3 & $1-2$ & $1-2$ & $1-2$ \\
\hline Mirabelle de Nancy & $5-6$ & $4-5$ & 5 & $4-5$ & 5 & 6 & 0 & 3 & 1 & 1 & $1-2$ \\
\hline Mohawk & 6 & 6 & 6 & 5 & $5-6$ & 6 & 0 & $2-3$ & 2 & 2 & 2 \\
\hline Moldavszkaja & 5 & 5 & $5-6$ & 5 & 5 & 6 & $0-1$ & $2-3$ & $1-2$ & 2 & 2 \\
\hline Monarch & $5-6$ & 6 & 6 & $5-6$ & $5-6$ & 6 & 0 & 3 & 2 & 2 & 2 \\
\hline Monsieur Hâtive & 6 & 5 & 6 & 5 & $5-6$ & 6 & 0 & 3 & 2 & 2 & 3 \\
\hline Montfort & $5-6$ & $4-5$ & $5-6$ & $4-5$ & 5 & 7 & 0 & $3-4$ & 2 & 1 & $2-3$ \\
\hline Nagrada & $5-6$ & $5-6$ & $5-6$ & 5 & 6 & 6 & 0 & 3 & $1-2$ & 2 & $1-2$ \\
\hline Nagy cukor & 5 & 6 & 6 & 5 & 5 & 6 & 0 & 3 & 2 & $1-2$ & 2 \\
\hline
\end{tabular}


Continuation of Table 1

\begin{tabular}{|c|c|c|c|c|c|c|c|c|c|c|c|}
\hline Species, cultivar & TB & WB & $\mathrm{RB}$ & NB & LB & $\mathrm{KB}$ & SB & $\mathrm{OP}$ & FR & SS & DR \\
\hline Nagybányai Besztercei & $5-6$ & $5-6$ & $5-6$ & 5 & 6 & 6 & 0 & 2 & $1-2$ & $2-3$ & 2 \\
\hline Nagyherceg & 6 & 6 & 6 & 5 & $5-6$ & 6 & 0 & 3 & $1-2$ & 1 & 2 \\
\hline Nancy-i ringló & 6 & 6 & $5-6$ & 5 & 6 & 6 & 0 & 4 & 2 & 2 & 1 \\
\hline Nemtudom szilva & 5 & 6 & $5-6$ & 5 & $5-6$ & 6 & 0 & 1 & $1-2$ & $1-2$ & $1-2$ \\
\hline Normann perdrigon & 6 & $5-6$ & 6 & 5 & $5-6$ & $5-6$ & 0 & $2-3$ & $2-4$ & $2-3$ & 2 \\
\hline Nubiana & 7 & 6 & 6 & 6 & 6 & 6 & 0 & 3 & 2 & 2 & 2 \\
\hline Nyári aszaló & 5 & $5-6$ & 5 & $4-5$ & 5 & $5-6$ & 0 & 2 & 1 & $2-3$ & 1 \\
\hline Obilnaja & 7 & $5-6$ & 5 & 5 & $6-7$ & 5 & 0 & 3 & 3 & $1-2$ & $1-2$ \\
\hline October Sun & $6-7$ & 6 & 6 & 5 & $6-7$ & $6-7$ & 0 & 4 & 2 & 2 & 2 \\
\hline Oka & $6-7$ & 5 & 6 & 4 & $6-7$ & 7 & 0 & $2-3$ & 2 & $1-2$ & 2 \\
\hline Októberi violaszínű & $5-6$ & 6 & 6 & 5 & 6 & 6 & 0 & $3-4$ & $2-3$ & 2 & 2 \\
\hline Oktrjabszkaja & 6 & 6 & $5-6$ & 6 & 6 & 6 & 0 & $3-4$ & 2 & $2-3$ & $2-3$ \\
\hline Olasz kék & 5 & $6-7$ & 6 & $5-6$ & 6 & $5-6$ & 0 & $3-4$ & 2 & 3 & $2-3$ \\
\hline Olasz zöld & $5-6$ & $5-6$ & $5-6$ & $5-6$ & 6 & $5-6$ & 0 & $3-4$ & 2 & $2-3$ & $2-3$ \\
\hline Onderka damaszcena & 5 & $5-6$ & $5-6$ & $5-6$ & $5-6$ & 6 & 0 & 2 & $1-2$ & 2 & 2 \\
\hline Oneida & 5 & $6-7$ & 6 & 5 & 6 & 6 & 0 & $2-3$ & 2 & 2 & 2 \\
\hline Ontario & $5-6$ & 5 & $5-6$ & $4-5$ & 5 & $5-6$ & 0 & $1-2$ & 1 & $1-2$ & $1-2$ \\
\hline Opal & 6 & 5 & $5-6$ & 5 & $5-6$ & $5-6$ & 0 & 2 & $1-2$ & 2 & 2 \\
\hline Óriás & 6 & $5-6$ & 5 & 5 & $5-6$ & 5 & 0 & 2 & $2-3$ & 2 & $1-2$ \\
\hline Orsó szilva & 5 & $5-6$ & 5 & $4-5$ & $5-6$ & $5-6$ & 0 & $1-2$ & 2 & 1 & 2 \\
\hline Ozark Premier & $6-7$ & 5 & 5 & 4 & $6-7$ & $6-7$ & 0 & 2 & 3 & 2 & $2-3$ \\
\hline Öreglaki korai & 5 & $5-6$ & 5 & 5 & 6 & 6 & $0-1$ & $1-2$ & 1 & $1-2$ & $1-2$ \\
\hline Öszi aszaló & $5-6$ & $5-6$ & $5-6$ & 5 & $5-6$ & 6 & 0 & 2 & 1 & $2-3$ & 2 \\
\hline Őszi ringló & 6 & $5-6$ & $5-6$ & 5 & 6 & 6 & 0 & $2-3$ & $2-3$ & 2 & 2 \\
\hline Pacific & $5-6$ & 5 & 5 & 5 & $5-6$ & 6 & 0 & 4 & 2 & $1-2$ & $1-2$ \\
\hline Paczelt szilvája & 6 & $5-6$ & 5 & 5 & 6 & $6-7$ & 0 & 3 & 2 & 2 & 2 \\
\hline Panyolai & 5 & $5-6$ & $5-6$ & 5 & $5-6$ & 6 & 0 & 1 & $1-2$ & 2 & 1 \\
\hline Pauline Schlechter & $5-6$ & $5-6$ & 5 & 5 & $5-6$ & 6 & 0 & 4 & $3-4$ & $2-3$ & 2 \\
\hline Penyigei & 5 & $5-6$ & $5-6$ & 5 & 6 & 6 & 0 & 1 & $1-2$ & 2 & 1 \\
\hline Perfection & 6 & 6 & 5 & 5 & 6 & $6-7$ & 0 & 3 & 2 & $1-2$ & 2 \\
\hline Pescarus & $5-6$ & $5-6$ & 5 & 5 & $5-6$ & 6 & 0 & 3 & 1 & 2 & 1 \\
\hline Piros cseresznyeszilva & 5 & $5-6$ & $5-6$ & 5 & $5-6$ & 6 & 0 & 3 & 1 & $1-2$ & 1 \\
\hline Piros tojás & 6 & 6 & 6 & $5-6$ & $5-6$ & 6 & 0 & 3 & 2 & 2 & $2-3$ \\
\hline Piros Washington & $5-6$ & 6 & $5-6$ & $5-6$ & 6 & $6-7$ & 0 & 3 & $1-2$ & 2 & 2 \\
\hline Plovdivna deszertna & 5 & 5 & 6 & $5-6$ & 5 & 5 & 0 & $2-3$ & 1 & $2-3$ & 1 \\
\hline Plovdivna szinja & $5-6$ & 5 & 6 & 5 & 5 & $5-6$ & 0 & $2-3$ & 1 & 3 & 1 \\
\hline Pond's seedlling & $5-6$ & $5-6$ & $5-6$ & $5-6$ & 5 & 6 & 0 & 3 & $1-2$ & $1-2$ & $1-2$ \\
\hline Pontbrianti szilva & 7 & 6 & 6 & $5-6$ & $5-6$ & $6-7$ & 0 & $3-4$ & $2-3$ & $1-2$ & 2 \\
\hline Poźegača & $5-6$ & 6 & $5-6$ & $5-6$ & 5 & 6 & 0 & 2 & 1 & 2 & 1 \\
\hline Pozna Plava & 5 & 6 & $5-6$ & 5 & $5-6$ & 6 & 0 & 2 & 1 & 2 & 1 \\
\hline Precoce di Giugno & $6-7$ & 6 & 6 & $5-6$ & 6 & 6 & 0 & 3 & 2 & 2 & 2 \\
\hline Presenta & 6 & 5 & $5-6$ & $5-6$ & 6 & $5-6$ & 0 & 1 & $1-2$ & $1-2$ & $2-3$ \\
\hline President & 6 & $5-6$ & 5 & 5 & $5-6$ & 5 & 0 & $1-2$ & 1 & 2 & $2-3$ \\
\hline Prettini & 6 & $5-6$ & 5 & 6 & 5 & 6 & 0 & 2 & 2 & 2 & $1-2$ \\
\hline Primate & $6-7$ & 6 & $5-6$ & $5-6$ & $5-6$ & $5-6$ & 0 & $2-3$ & 2 & $2-3$ & 2 \\
\hline Prince császár & $5-6$ & $5-6$ & $5-6$ & $5-6$ & 6 & 6 & 0 & $3-4$ & 2 & 2 & $1-2$ \\
\hline
\end{tabular}


Continuation of Table 1

\begin{tabular}{|c|c|c|c|c|c|c|c|c|c|c|c|}
\hline Species, cultivar & $\mathrm{TB}$ & WB & $\mathrm{RB}$ & NB & LB & $\mathrm{KB}$ & SB & $\mathrm{OP}$ & FR & SS & DR \\
\hline Prince piros ringló & $5-6$ & 6 & 6 & $5-6$ & 6 & $6-7$ & 0 & 3 & $1-2$ & 2 & 1 \\
\hline Procureur & 6 & 6 & 6 & $5-6$ & 6 & 6 & 0 & 3 & 2 & 2 & 2 \\
\hline Prune d'Ente 686 & 6 & 6 & 5 & $4-5$ & 6 & 5 & 0 & 3 & $1-2$ & 2 & 2 \\
\hline Prune d'Ente 707 & 6 & $5-6$ & 5 & 5 & 6 & 5 & 0 & 3 & $1-2$ & 2 & $1-2$ \\
\hline Prune Large Black & $5-6$ & 5 & $5-6$ & $5-6$ & 6 & $5-6$ & 0 & 3 & 3 & 2 & 2 \\
\hline Purpurovaja & $6-7$ & $4-5$ & $5-6$ & 4 & $6-7$ & 7 & $0-1$ & 2 & 2 & $2-3$ & $1-2$ \\
\hline Queston & $5-6$ & 6 & $5-6$ & 5 & 6 & 6 & 0 & 2 & $1-2$ & 2 & 2 \\
\hline Rademaekers szilva & 6 & $5-6$ & 6 & $5-6$ & 6 & 6 & 0 & $3-4$ & 2 & $2-3$ & 2 \\
\hline Reine-Claude de Bavay & 6 & $5-6$ & $5-6$ & 5 & 6 & 6 & 0 & $2-3$ & $1-2$ & 2 & 2 \\
\hline Reine-Claude d'Oullins & $6-7$ & 5 & $5-6$ & $5-6$ & 6 & $6-7$ & 0 & 3 & 2 & 2 & 2 \\
\hline Reizensteini sárga & $5-6$ & $5-6$ & $5-6$ & 5 & $5-6$ & $5-6$ & 0 & 3 & $2-3$ & $2-3$ & $2-3$ \\
\hline Révfülöpi & 6 & $5-6$ & 5 & 5 & 6 & $6-7$ & 0 & 3 & 2 & 2 & 2 \\
\hline Richards Early Italian & $5-6$ & $5-6$ & 6 & 6 & $5-6$ & 6 & 0 & 3 & 2 & $2-3$ & 2 \\
\hline Rigny admirális & 5 & $5-6$ & $5-6$ & 5 & 6 & $5-6$ & 0 & 3 & $2-3$ & $2-3$ & $2-3$ \\
\hline Rizkova & $5-6$ & 6 & $5-6$ & 5 & $5-6$ & $5-6$ & 0 & $1-2$ & 1 & $2-3$ & 1 \\
\hline Roter Spilling & $5-6$ & $5-6$ & 5 & $5-6$ & 6 & 6 & 0 & 2 & 1 & $1-2$ & $1-2$ \\
\hline Royer kajszilszilva & 6 & $5-6$ & $5-6$ & 5 & $5-6$ & $5-6$ & 0 & 3 & $2-3$ & 1 & 2 \\
\hline Rózsaszilva C. 1505 & $6-7$ & 6 & 6 & $5-6$ & $5-6$ & 6 & 0 & 2 & 2 & 2 & 3 \\
\hline Rubysweet & $6-7$ & 6 & 6 & 6 & 6 & 6 & 0 & 3 & 2 & 2 & 2 \\
\hline Ruth Gerstetter & 6 & $5-6$ & $5-6$ & 5 & 6 & 6 & 0 & 3 & 2 & 1 & $2-3$ \\
\hline Saint-Étienne-i szilva & $5-6$ & $5-6$ & 5 & $5-6$ & 5 & $5-6$ & 0 & 3 & 1 & 2 & $2-3$ \\
\hline Santa Rosa & $6-7$ & 5 & 5 & 4 & 5 & 7 & $0-1$ & $2-3$ & $1-2$ & 1 & $1-2$ \\
\hline Sárga kajszinszilva & 6 & 6 & 6 & $5-6$ & $5-6$ & 6 & 0 & 3 & $2-3$ & $1-2$ & 2 \\
\hline Sárga mirabella & 6 & $5-6$ & $5-6$ & $5-6$ & 6 & 6 & 0 & 1 & 1 & $1-2$ & $1-2$ \\
\hline Sár ringló & $5-6$ & $5-6$ & 6 & 6 & $6-7$ & 6 & 0 & $3-4$ & 2 & 2 & 1 \\
\hline Sárga szilva C. 1501 & 6 & $5-6$ & $5-6$ & 6 & 6 & $6-7$ & 0 & 3 & 2 & 2 & 2 \\
\hline Sárga tojás & 6 & $5-6$ & $5-6$ & $5-6$ & $5-6$ & 6 & 0 & 3 & $2-3$ & 2 & $1-2$ \\
\hline Sárga úri & $5-6$ & $5-6$ & $5-6$ & 5 & 5 & 6 & 0 & 2 & $1-2$ & 2 & $1-2$ \\
\hline Sasbachi korai & $5-6$ & $5-6$ & $5-6$ & $5-6$ & 5 & $5-6$ & 0 & $2-3$ & 2 & 2 & $1-2$ \\
\hline Satsuma & $6-7$ & 6 & 6 & 6 & $5-6$ & 6 & 0 & $2-3$ & 3 & $2-3$ & 2 \\
\hline Schallers Lahrer Frühzwetsche & 5 & $5-6$ & 5 & $5-6$ & $5-6$ & 6 & 0 & $2-3$ & $2-3$ & 2 & 2 \\
\hline Schwäbische Frühzwetsche & $5-6$ & 6 & $5-6$ & $5-6$ & $5-6$ & $5-6$ & 0 & 2 & $2-3$ & 2 & 2 \\
\hline Sejenov & 6 & 6 & $5-6$ & $5-6$ & $5-6$ & $5-6$ & 0 & 2 & 2 & 2 & 2 \\
\hline Sermina & 6 & 5 & 5 & 5 & 5 & 6 & 0 & 3 & 2 & 1 & 1 \\
\hline Sharp császárszilva & $5-6$ & $5-6$ & $5-6$ & $5-6$ & 5 & 6 & 0 & $1-2$ & $2-3$ & $2-3$ & $2-3$ \\
\hline Shiro & 7 & 6 & 6 & $5-6$ & 6 & $6-7$ & 0 & $1-2$ & $1-2$ & $1-2$ & 2 \\
\hline Silvia & $6-7$ & 5 & 5 & 5 & $5-6$ & 6 & 0 & 3 & $2-3$ & 2 & $2-3$ \\
\hline Simka & 7 & 5 & 5 & $4-5$ & $5-6$ & $5-6$ & 0 & $3-4$ & 2 & 1 & 1 \\
\hline Slapanicka & $5-6$ & 6 & $5-6$ & $5-6$ & $5-6$ & 6 & 0 & 2 & 1 & $2-3$ & 1 \\
\hline Smith úri & 6 & $5-6$ & $5-6$ & 6 & $5-6$ & 6 & 0 & $2-3$ & $2-3$ & 2 & 2 \\
\hline Sötétkék tojás & $5-6$ & $5-6$ & $5-6$ & $5-6$ & 6 & 6 & 0 & 3 & 2 & 2 & 1 \\
\hline Soriso de primavera & $6-7$ & 6 & 6 & 6 & 6 & $6-7$ & 0 & 2 & 2 & $1-2$ & 2 \\
\hline Späth Anna & $5-6$ & 4 & 5 & $4-5$ & $5-6$ & $5-6$ & 0 & 3 & 2 & 2 & $2-3$ \\
\hline Späth legkorábbi & 6 & 5 & $5-6$ & 5 & $5-6$ & $5-6$ & 0 & 2 & 2 & $1-2$ & $1-2$ \\
\hline Späth Vilma & 6 & $5-6$ & $5-6$ & 5 & 5 & 6 & 0 & 2 & 2 & 1 & $2-3$ \\
\hline Spendlor & $5-6$ & $5-6$ & $5-6$ & 5 & $5-6$ & 6 & 0 & $2-3$ & $2-3$ & 2 & $2-3$ \\
\hline
\end{tabular}


Continuation of Table 1

\begin{tabular}{|c|c|c|c|c|c|c|c|c|c|c|c|}
\hline Species, cultivar & TB & WB & $\mathrm{RB}$ & NB & LB & $\mathrm{KB}$ & SB & OP & FR & SS & DR \\
\hline St. Julien A & $5-5$ & $5-6$ & 5 & $5-6$ & 5 & 6 & 0 & 2 & 1 & $1-2$ & 2 \\
\hline St. Julien B & $5-6$ & 5 & $5-6$ & 5 & $5-6$ & 6 & 0 & $1-2$ & $1-2$ & 1 & 2 \\
\hline St. Julien C & 5 & $5-6$ & 5 & $5-6$ & 5 & $5-6$ & 0 & 2 & $1-2$ & 2 & 2 \\
\hline Stanley & 6 & 5 & 5 & 5 & 6 & 6 & 0 & 2 & $1-2$ & $1-2$ & $1-2$ \\
\hline Stanley NDK & 6 & 5 & $5-6$ & 5 & 6 & 6 & 0 & $2-3$ & 1 & 1 & 1 \\
\hline Stanley Ny. 140 & 6 & 5 & $5-6$ & 5 & $5-6$ & $5-6$ & 0 & 2 & 1 & $1-2$ & 1 \\
\hline Stanley Román & 6 & 5 & 5 & 5 & $5-6$ & $5-6$ & 0 & $2-3$ & 1 & $1-2$ & $1-2$ \\
\hline Stanley Yugoslav & 6 & 5 & 5 & 5 & $5-6$ & $5-6$ & 0 & 2 & 1 & 1 & 1 \\
\hline Starking Delicious & 7 & 6 & $5-6$ & $5-6$ & 6 & $6-7$ & 0 & 4 & 2 & 2 & 2 \\
\hline Sugar Prune & 6 & $5-6$ & $5-6$ & 5 & 6 & 5 & 0 & 3 & 2 & 2 & $1-2$ \\
\hline Sugar Top & 6 & 6 & 5 & $5-6$ & $5-6$ & $5-6$ & 0 & 2 & 2 & 2 & 2 \\
\hline Svehova & 6 & $5-6$ & $5-6$ & 5 & $5-6$ & 6 & 0 & 2 & $1-2$ & $2-3$ & 2 \\
\hline Sweet Autumn & $6-7$ & 5 & $5-6$ & 5 & 7 & $6-7$ & 0 & 3 & $2-3$ & $2-3$ & 2 \\
\hline Szakarka & $5-6$ & $5-6$ & $5-6$ & 5 & $5-6$ & $5-6$ & 0 & $2-3$ & 2 & 2 & $1-2$ \\
\hline Szarvasi & $5-6$ & 5 & $5-6$ & $4-5$ & $5-6$ & 6 & 0 & 3 & 2 & $2-3$ & 2 \\
\hline Szent Katalin & $5-6$ & 5 & $5-6$ & 5 & $5-6$ & 6 & 0 & 3 & 2 & $2-3$ & 2 \\
\hline Szeptemberi füszeres mirabella & $5-6$ & $5-6$ & 5 & $5-6$ & 5 & 6 & 0 & $1-2$ & $1-2$ & 2 & $1-2$ \\
\hline Szigeti zöld & 6 & 6 & $5-6$ & $5-6$ & $5-6$ & 6 & 0 & 4 & 2 & 2 & $1-2$ \\
\hline Szívalakú cseresznyeszilva & 5 & 5 & 5 & $5-6$ & 5 & $5-6$ & 0 & 4 & 2 & 1 & 2 \\
\hline Szopornyica & 6 & 6 & 6 & $5-6$ & $5-6$ & $5-6$ & 0 & $3-4$ & $2-3$ & $2-3$ & $2-3$ \\
\hline Sztrumszka & $5-6$ & $5-6$ & 5 & $5-6$ & 5 & 6 & $0-1$ & $2-3$ & 2 & 2 & 2 \\
\hline Szüzpiros szilva & $5-6$ & $5-6$ & $5-6$ & 5 & 5 & $5-6$ & 0 & 4 & 2 & 2 & 2 \\
\hline Tardicotes & $6-7$ & 6 & $5-6$ & 5 & $5-6$ & 6 & 0 & 3 & $1-2$ & 2 & $2-3$ \\
\hline Tarka perdrigon & $5-6$ & $4-5$ & 5 & $4-5$ & $5-6$ & 6 & 0 & 2 & 2 & 2 & 2 \\
\hline Tarka szilva & $5-6$ & 5 & $5-6$ & 5 & $5-6$ & $5-6$ & $0-1$ & 2 & $1-2$ & 1 & $2-3$ \\
\hline Tegera & $5-6$ & 5 & $5-6$ & $5-6$ & $5-6$ & 6 & 0 & 2 & $2-3$ & $2-3$ & 2 \\
\hline Timocanka & 6 & $5-6$ & $5-6$ & 5 & $5-6$ & $5-5$ & 0 & 2 & 1 & $1-2$ & $1-2$ \\
\hline Toka & 7 & 5 & $5-6$ & 5 & 6 & $5-6$ & 0 & 3 & 2 & 2 & 3 \\
\hline Top & $5-6$ & $5-6$ & $5-6$ & $5-6$ & $5-6$ & $5-6$ & 0 & 2 & $1-2$ & 2 & 2 \\
\hline Top 2000 & $5-6$ & $5-6$ & $5-6$ & 5 & $5-6$ & $5-6$ & 0 & 2 & 1 & $1-2$ & 2 \\
\hline Top Gigant Plus & $6-7$ & 6 & $5-6$ & 5 & 6 & 6 & 0 & 2 & 2 & 1 & 2 \\
\hline Top King & $5-6$ & $5-6$ & 5 & $5-6$ & $5-6$ & $5-6$ & 0 & $1-2$ & 1 & $1-2$ & $1-2$ \\
\hline Topend Plus & 6 & 6 & $5-6$ & $5-6$ & $5-6$ & 6 & 0 & $1-2$ & 1 & $1-2$ & $1-2$ \\
\hline Topfirst & 5 & $5-6$ & 6 & 5 & $5-6$ & $5-6$ & 0 & 2 & 1 & 2 & 2 \\
\hline Topfive & $5-6$ & 5 & 5 & $5-6$ & $5-6$ & $5-6$ & 0 & 2 & $1-2$ & $1-2$ & 2 \\
\hline Tophit & $5-6$ & $5-6$ & $5-6$ & 5 & $5-6$ & 6 & 0 & 2 & $1-2$ & $1-2$ & 2 \\
\hline Tophit Plus & 6 & 6 & $5-6$ & $5-6$ & $5-6$ & 6 & 0 & 2 & 2 & 2 & $1-2$ \\
\hline Topper & $5-6$ & 5 & 5 & $5-6$ & $5-6$ & $5-6$ & 0 & 2 & $1-2$ & 2 & $1-2$ \\
\hline Topstar Plus & 6 & 6 & 5 & 5 & 6 & 6 & 0 & 2 & $1-2$ & 2 & 2 \\
\hline Toptaste & 6 & 6 & $5-6$ & $5-6$ & $5-6$ & 6 & 0 & 2 & $1-2$ & $1-2$ & 1 \\
\hline Tragédia & $5-6$ & $5-6$ & $5-6$ & 5 & $5-6$ & 6 & 0 & 2 & $1-2$ & 2 & 2 \\
\hline Trojanszka szinja & $5-6$ & $5-6$ & $5-6$ & 5 & 5 & $5-6$ & 0 & 2 & $1-2$ & $2-3$ & $1-2$ \\
\hline Tuleu dulce & $5-6$ & 5 & 5 & 5 & $5-6$ & 6 & 0 & 3 & 2 & 2 & 3 \\
\hline Tuleu gras & $5-6$ & $5-6$ & 5 & 4 & 6 & 6 & $0-1$ & $1-2$ & $1-2$ & $1-2$ & 2 \\
\hline Tuleu timpuriu & 6 & $5-6$ & $5-6$ & 5 & $5-6$ & $6-7$ & 0 & $3-4$ & 2 & 2 & 3 \\
\hline Typ. 205 & 6 & 6 & 6 & $5-6$ & $5-6$ & $5-6$ & 0 & 3 & 2 & 2 & 2 \\
\hline
\end{tabular}


Continuation of Table 1

\begin{tabular}{|c|c|c|c|c|c|c|c|c|c|c|c|}
\hline Species, cultivar & TB & WB & $\mathrm{RB}$ & NB & LB & KB & SB & OP & FR & SS & DR \\
\hline Uhinksz ringló & $5-6$ & $5-6$ & $5-6$ & $5-6$ & $5-6$ & $5-6$ & 0 & 2 & 2 & 2 & 2 \\
\hline Uhlhorns Konservpflaume & 5 & 5 & $5-6$ & $5-6$ & 5 & 6 & 0 & 3 & 3 & $2-3$ & $2-3$ \\
\hline Utility & $6-7$ & $5-6$ & $5-6$ & 5 & $5-6$ & 6 & 0 & 3 & 3 & $2-3$ & 3 \\
\hline Üzbég Vengerka & 6 & 6 & 6 & $5-6$ & $5-6$ & 6 & $0-1$ & 3 & $1-2$ & 2 & 2 \\
\hline Valerija & $5-6$ & $5-6$ & $5-6$ & $5-6$ & 5 & 6 & 0 & $2-3$ & 2 & 2 & 2 \\
\hline Valjevka & 6 & 6 & $5-6$ & 5 & $5-6$ & 6 & 0 & 2 & 2 & 2 & 2 \\
\hline Valor & $5-6$ & $5-6$ & 5 & $5-6$ & 5 & $5-6$ & 0 & 2 & $1-2$ & 2 & 2 \\
\hline Van Mons piros szilvája & 5 & 5 & $5-6$ & $5-6$ & 5 & 6 & 0 & 4 & $3-4$ & 3 & 3 \\
\hline Vankova & 6 & 6 & 5 & $5-6$ & 5 & $6-7$ & $0-1$ & 3 & $2-3$ & 2 & $1-2$ \\
\hline Velkoplodna & $5-6$ & 6 & $5-6$ & $5-6$ & $5-6$ & 6 & 0 & $3-4$ & 2 & 2 & 2 \\
\hline Vengerka Kait & $5-6$ & $5-6$ & 5 & $5-6$ & $5-6$ & $5-6$ & $0-1$ & $2-3$ & 2 & 2 & $1-2$ \\
\hline Vérbélü szilva & $5-6$ & 5 & $5-6$ & 5 & $5-6$ & $5-6$ & 0 & 3 & 1 & 3 & 2 \\
\hline Verity & $5-6$ & $5-6$ & $5-6$ & $5-6$ & 5 & 6 & 0 & 3 & $1-2$ & 2 & $2-3$ \\
\hline Veres szilva (Tiszántúl) & 5 & 5 & 5 & 5 & $5-6$ & $5-6$ & $0-1$ & 2 & $1-2$ & 2 & $1-2$ \\
\hline Victoria & 5 & $4-5$ & $5-6$ & 5 & 5 & $5-6$ & 0 & 2 & $1-2$ & $2-3$ & $2-3$ \\
\hline Vineta Romanesti & 5 & $5-6$ & 6 & $5-6$ & $5-6$ & 6 & $0-1$ & $2-3$ & 2 & $1-2$ & $2-3$ \\
\hline Vinke korai & 5 & 5 & 5 & 6 & $5-6$ & $5-6$ & 0 & 2 & 2 & 2 & 1 \\
\hline Violaszínủ császárnő & $5-6$ & $5-6$ & $5-6$ & 6 & $5-6$ & 6 & 0 & 3 & 2 & $2-3$ & 2 \\
\hline Violaszínủ diapré & $5-6$ & 6 & 6 & $5-6$ & 5 & $5-6$ & $0-1$ & 3 & 2 & 2 & $1-2$ \\
\hline Violaszínű királyszilva & 6 & 6 & 6 & 6 & $5-6$ & 6 & 0 & 3 & 2 & $2-3$ & 2 \\
\hline Violaszínű korai perdrigon & $5-6$ & $5-6$ & $5-6$ & $5-6$ & 6 & 6 & 0 & 3 & $2-3$ & 2 & 2 \\
\hline Violaszínủ ringló & 6 & $5-6$ & $5-6$ & $5-6$ & 6 & 6 & 0 & 3 & 2 & $2-3$ & $2-3$ \\
\hline VIR Vengerka & 5 & 5 & 5 & $5-6$ & $5-6$ & $5-6$ & 0 & 2 & 2 & 2 & $1-2$ \\
\hline Voyageur & $6-7$ & 6 & 6 & 6 & $5-6$ & $5-6$ & 0 & $3-4$ & 3 & 3 & $2-3$ \\
\hline Vörös szilva (Duna-Tisza köze) & $5-6$ & $4-5$ & 5 & $4-5$ & $5-6$ & 6 & 0 & 2 & 1 & $1-2$ & 1 \\
\hline Walesi herceg & 6 & 5 & $5-6$ & 5 & 5 & 6 & 0 & 1 & 1 & 2 & $2-3$ \\
\hline Walter szilvája & $5-6$ & $5-6$ & $5-6$ & 5 & $5-6$ & $5-6$ & 0 & 3 & 3 & $2-3$ & 3 \\
\hline Wangenheim & $5-6$ & 5 & 5 & $4-5$ & $5-6$ & $5-6$ & 0 & $1-2$ & 2 & 1 & 21 \\
\hline Wanka & $6-7$ & 6 & $5-6$ & 5 & 6 & 5 & 0 & $3-4$ & $2-3$ & $2-3$ & $2-3$ \\
\hline Waschmann Berta & 6 & $5-6$ & 5 & $5-6$ & $5-6$ & $5-6$ & 0 & 3 & $2-3$ & 2 & $2-3$ \\
\hline Washington & 6 & 6 & $5-6$ & 6 & $5-6$ & $5-6$ & 0 & $2-3$ & $1-2$ & 2 & 2 \\
\hline Waught & 7 & 6 & 6 & 6 & 5 & 6 & 0 & 4 & $3-4$ & $2-3$ & 2 \\
\hline Wiener Frühzwetsche & 6 & 5 & $5-6$ & 5 & $5-6$ & 6 & 0 & 3 & $2-3$ & $1-2$ & 2 \\
\hline Willamate & 5 & 5 & $5-6$ & 5 & $5-6$ & $5-6$ & 0 & 3 & 2 & 2 & 2 \\
\hline Wolf & $6-7$ & 6 & 6 & $5-6$ & $5-6$ & 6 & 0 & 4 & 3 & $2-3$ & 3 \\
\hline Yakima & $5-6$ & 5 & 5 & 5 & 6 & 6 & $0-1$ & $3-4$ & $1-2$ & 1 & $1-2$ \\
\hline Zerterfleth & 6 & 5 & $5-6$ & 5 & 6 & 6 & 0 & $2-3$ & $2-3$ & 2 & $2-3$ \\
\hline Zimmer's Frühzwetsche & $5-6$ & $5-6$ & $5-6$ & 5 & $5-6$ & 6 & 0 & 3 & 2 & 2 & 2 \\
\hline Zlatka & $6-7$ & $5-6$ & 5 & $5-6$ & 6 & $5-6$ & 0 & 2 & $1-2$ & $1-2$ & $1-2$ \\
\hline Zöld datolya & $5-6$ & 5 & $5-6$ & 5 & 6 & $5-6$ & 0 & 3 & $2-3$ & 2 & $2-3$ \\
\hline Zöld ringló & 6 & 5 & 5 & 5 & 6 & 6 & 0 & $3-4$ & 2 & $1-2$ & $1-2$ \\
\hline Zwetschenbastard No. 2 & $5-6$ & $5-6$ & 5 & 5 & $5-6$ & 6 & 0 & $2-3$ & 2 & 2 & 2 \\
\hline Zsolta afazka & 6 & 5 & $5-6$ & 5 & 6 & 6 & $0-1$ & $1-2$ & $1-2$ & $1-2$ & $1-2$ \\
\hline Zsnyivka & $5-6$ & $5-6$ & 5 & 5 & $5-6$ & 6 & 0 & 2 & 2 & 2 & 2 \\
\hline
\end{tabular}


Table 2. Relative ecological indicator values of plum cultivars

\begin{tabular}{|l|c|c|c|}
\hline \multicolumn{1}{|c|}{$\begin{array}{c}\text { Relative ecological } \\
\text { indicators }\end{array}$} & Interval & Mean & $\mathrm{CV}, \%$ \\
\hline Temperature figures(TB) & $5 \rightarrow 7$ & $5.79 \pm 0.49$ & 8.5 \\
\hline Moisture figures(WB) & $4 \rightarrow 7$ & $5.56 \pm 0.43$ & 7.8 \\
\hline Reaction figures (RB) & $4 \rightarrow 7$ & $5.48 \pm 0.38$ & 7.0 \\
\hline Nitrogen figures (NB) & $4 \rightarrow 6$ & $5.17 \pm 0.42$ & 8.1 \\
\hline Light figures (LB) & $4 \rightarrow 7$ & $5.57 \pm 0.43$ & 7.7 \\
\hline Continentality values (KB) & $4 \rightarrow 7$ & $5.83 \pm 0.43$ & 7.4 \\
\hline Salt figures (SB) & $0 \rightarrow 1$ & $0.04 \pm 0.13$ & 347.5 \\
\hline Open pollination (OP) & $1 \rightarrow 4$ & $2.62 \pm 0.74$ & 28.0 \\
\hline Frost resistance (FR) & $1 \rightarrow 3$ & $1.84 \pm 0.55$ & 29.0 \\
\hline Sharka sensitivity (SS) & $0 \rightarrow 3$ & $1.96 \pm 0.47$ & 24.0 \\
\hline Disease resistance (DR) & $1 \rightarrow 3$ & $1.88 \pm 0.58$ & 27.6 \\
\hline
\end{tabular}

\section{References}

Bellini, E. - Liverani, A. - Nicotra, A. - Sansavini, S. (1982): Osservazioni su cultivar di recente intruzione e reviaione delle liste varietali del susino. Fruttic. Ital. 44 (12): 39-55.

Bereczki, M. (1877-1887): Gyümölcsészeti vázlatok I-IV. Réthi Gyulai Kiadása, Arad.

Borhidi A. (1969): Adatok a kocsánytalan tölgy (Quercus petraea fajcsoport) és a molyhos tölgy (Quercus pubescens fajcsopoort) kistájainak ökológiai-cönológiai magatartásához. Bot. Közlem. 56: 155-158.

Borhidi A. 1993. A magyar flóra sociális magatartástípusai, természetességi és relatív ökológiai értékszámai. KTM Term. véd. Hiv. Janus Pann. Tud. Egy., Pécs.

Borhidi A. 1995. Social behaviour types, the naturalness and relative ecological indicator values of the higher plants in the Hungarian flora. Acta Bot. Hung. 39: 97-181.

Bordeianu, T. - Constantinescu, N. - Stefan, N. (edit. ) (1965): Prunul, ciresul, visinul, cornul. Pomol. Rep. Soc. Rom. IV. Edit. Acad. Rep. Soc. Rom., Bucuresti.

Bordeianu, T. - Constantinescu, A. - Stefan, N. (edit.) (1969): Soiuri noi si hibridi de perspetiva. Pomol. Rep. Soc. Rom. VIII. Edit. Acad. Rep. Soc. Rom., Bucuresti.

Brózik, S. (1960): Csonthéjas gyümölcsüek: Szilva, kajszi. Mezögazdasági Kiadó, Bp.

Brózik, S. - Nyéki, J. (1975): Gyümölcstermő növények termékenyülése. Mezőgazdasági Kiadó, Bp.

Crane, M. B. - Lawrence, W. J. C. (1956): The genetics of garden plants. MacMillan Co. Press, London.

Csöbönyei, I. (1957-1970): Fenológiai naplók (kézirat). DuTiMeKi Gyüm. term. Oszt., Cegléd.

Dahl, C. G. (1935): Morphological studies of plum flowers. Meded. perm. Komm. Fruktod. Förs. 38: 1-93.

Dermine, E. - Liard, O. (1957): Identification et description de varietés du prunier Européen. Duculot-Maison Rustique, Gemblaux - Paris.
Dermine, E. - Liard, O. (1978): Identification et description de varietés du prunier Européen. II ${ }^{\text {partie }}$ I. R. S. I. A., Gemblaux.

Ellenberg, H. (1950): Landwirtschaftliche Pflanzensoziologie I. Unkrautgemeinschaften als Zeiger für Klima und Boden. Ulmer Verlag, Stuttgart.

Ellenberg, H. (1952): Landwirtschaftliche Pflanzensoziologie II. Wiesen und Weiden und ihre standortliche Bewertung. Ulmer Verlag, Stuttgart.

Ellenberg, H. (1963): Ökologische Beiträge zur Umweltgestaltung. Ulmer Verlag, Stuttgart.

Ellenberg, H. (1974) Zeigerwerte der Gefasspflanzen Mitteleuropas. Scripta Geobot. IX. Goltze Verlag, Göttingen.

Ellenberg, H. - Weber, H. E. - Düll, R. -Wirth, W. - Werner, W. - Paulissen, D. (1991):Zeigeiwerte von Pflanzen in Mitteleuropa. Scripta Geobot. XVIII. Goltze Verlag, Göttingen.

Faust, M. (1989): Physiology of temperate zone fruit trees. J. Wiley and Sons, New York - Chichester - Brisbane - Toronto Singapure.

Faust, M. - Surányi, D. (1997): Origin and dissemination of plums. Hort. Rev. N. Y. 19: 263-317.

Faust, M. - Surányi, D. - Gradziel, T. - Timon, B. - Nyujtó, F. (edit. Janick, J.) (2011): Origin and dissemination of Prunus. Scripta Horticult. 11: 1-241.

Gardner, V. R. - Bradford, F. Ch. - Hooker, H. D. Jr. (1952): The fundamentals of fruit production. McGraw-Hill Book Co., New York - Toronto - London.

G. Tóth, M. (1997): Gyümölcsészet. Primom Váll. Alap., Nyíregyháza.

Gyulai, F. (2001): Archeobotanika. A kultúrnövények története a Kárpát-medencében a régészeti-növénytani vizsgálatok alapján. Jószöveg Kiadó, Bp.

Gyuró, F. (edit.) (1974): A gyümölcstermesztés alapjai. Mezőgazdasági Kiadó, Bp

Gyuró, F. (edit.) (1990): Gyümölcstermesztés. Mezőgazdasági Kiadó, Bp.

Hedrick, U. P. - Wellington, N, R. - Taylor, O. M. - Alderman, W. H. - Dorsey, M. J. (1911): The plums of New York. N. Y. Sta. Agric. Exp. Sta. 3 (2): 1-616.

Holb, I. J. - Drén, G. - Thurzó, S. - Erdős, Z. - Soltész, M. Szabó, Z. (2007): Incidence of virus and fungal diseases on apricot, cherry and plum cultivars in Hungary. Intern. J. Hort. Sci. 13 (1): 29-32.

Iversen, J. (1936): Biologische Pflanzentypen als Hilfsmittel in der Vegetationsforschung. Levin und Munksgaard, Kopenhagen. 224.

Jávorka, S. - Soó, R. (1951): A magyar növényvilág kézikönyve I-II. Akadémiai Kiadó, Bp.

Kárpáti, I. (1978): Magyarországi vizek és ártéri szintek növényfajainak ökológiai besorolása. Keszth. Agrártud. Egy. Kiadv. 20: 5-62.

Kárpáti, Z. - Terpó, A. (1971): Alkalmazott növényföldrajz. Mezőgazdasági Kiadó, Bp.

Knight, R. L. (1969): Abstract bibliograhy of fruit breeding and genetics to 1965. Prunus. Comm. Agric. Bur. (CAB), East Malling.

Kobel, F. (1954): Lehrbuch des Obstbaus auf phsiologischer Grundlage. Springer Verlag, Berlin.

Kovács, J. A. (1979): Indicatorii biologici, ecologici si economici ai florei pajistilor. Minist. Agricult. si Ind. Aliment., Bucuresti. 
Kozma, P. - Nyéki, J. - Soltész, M. - Szabó, Z. (edit.) (2003): Floral biology, pollination and fertilisation in temperate zone fruit species and grape. Akadémiai Kiadó, Bp.

Larcher, W. (1980): Physiological plant ecology. Springer Verlag, Berlin - Heidelberg - New York.

Mándy Gy. (1963): Kertészeti növények nemesítése táblázatokban. Mezőgazdasági Kiadó, Bp.

McGregor, S. E. (1976): Insect pollination of cultivated crop plants. U.S. Dept. Agric., Washington.

Meusel, H. - Schubert, R. (1972): Volk und Wissen. Akademie Verlag, Berlin

Nicotra, A. - Moser, L. - Cobianchi, D. - Damiano, C. - Faedi, W. (1983): Monografia di cultivar di susino.Edagricole, Roma.

Nyéki, J. (szerk.) (1980): Gyümölcsfajták virágzásbiológiája és termékenyülése. Mezőgazdasági Kiadó, Bp.

Nyéki, K. - Soltész, M. (edit.) (1996): Floral biology of temperate zone fruit trees and small fruits. Akadémiai Kiadó, Bp.

Nyéki, J. - Soltész, M. - Szabó, Z. (2012): Minőségi szilvatermesztés. DE AGTC, Kertészeti Intézet, Debrecen.

Papp J. (szerk.) (2003): 1. Gyümölcstermesztési alapismeretek. mezőgazda Kiadó, Bp.

Papp J. (szerk.) (2004): 2. A gyümölcsök termesztése. Mezőgazda Kiadó, Bp.

Papp, J. - Tamási, J. (1979): Gyümölcsösök talajművelése és tápanyagellátottsága. Mezőgazdasági Kiadó, Bp.

Pernesz Gy. (2013): Nemzeti fajtajegyzék - National list of varieties. Gyümölcs - Fruit. NÉBIH, Bp. ISSN 1585-8308

Pichler, F. - Karrer, G. (1991): Comparison of different ecological indicator value systems. in: Horváth, F.(edit.): Poster Abstracts 34th IAVS Symposium, Eger, Hungary. p. 102-104.

Porpáczy A. (edit.) (1964): A korszerü gyümölcstermesztés elméleti kérdései. Mezőgazdasági Kiadó, Bp.

Précsényi, I. (1986): The acoluthic space and its importance in the ecologicai research. Acta Bot. Hung. 32: 53-60.

Ramming, D. W. - Cociu, V. (1991): Plums (Prunus). In:Genetic recources of temperature fruit and nut crops vol. I-II. eds. Moore, J. N. -Ballington, R, Jr. ISHS, Wageningen. p. 235-287.

Raunkiaer, C. (1905): Types biologiques pour la géographie botanique. Oversigt over Det Kongel. Danske Videnskab. Selsk. Forhandl. p. 347-438.

Roach, F. A. (1985): Cultivated fruits of Britain. Their origin and history. Basil Blackwill Public. Ltd., Oxford-New York.

Röder, K. (1940): Sortenkundliche Untersuchungen an Prunus domestica L. Kühn.-Archiv B54: 1-132.

Rybin, V.A. (1935): An experiment on the synthesis of the domestic plum from related wild species. Trudi priklad. Bot. Gaz. Szelekt. Ser. A15: 87-100.

Rybin, V. A. (1936): Naturally and expermentaslly produced hybrids between the blacktorn and cherry plum, and the problem of the heredity of the domestic plum. Planta 25: 22-58.

Rybin, V. A. (1962): Hexaploid hybrids of Prunus (Prunophora section) and their significance. Proc. 16th Intern. Hort. Congr. Brussels 1: 173.

Scherfose, V. (1990): Salz-Zeigerwerte von Gefásspflanzen der Salzmarschen Tideröhrichte und Salzwassertümpel an der deutschen Nord- und Ostseeküste. Jb. Nieders. Landesamt Wasser und Abfall, Forsch. stelle Küste 39: 31-82
Schwanitz, (1973): A kultúrnövények keletkezése: az egész növényvilág evolúciós modellje.Mezőgazdasági Kiadó, Bp.

Simon, T. (1988): A hazai edényes flóra természetvédelmi értékbesorolása. Abstr. Bot. 2: 1-23.

Simon, T. (1991): A magyarországi edényes flóra határozója (Harasztok - Virágos növények). Nemzeti Tankönyvkiadó, Bp.

Soltész, M. (edit.) (1998): Gyümölcsfajta-ismeret és-használat. Mezőgazda Kiadó, Bp. Soltész, M. (szerk.) (2014): Magyar Gyümölcsfajták. Mezőgazda Kiadó, Bp.

Soó, R. (1964-1985): A magyar flóra és vegetáció rendszertaninövényföldrajzi kézikönyve I-VII. köt. Akadémiai Kiadó, Bp.

Surányi D. (1985): Kerti növények regénye. Mezőgazdasági Kiadó, Bp.

Surányi D. (1986): Phenometrical characterestics of plums, regarding the air temperate requirements of flowering and ripening. Acta Agron. Hung. 35: 63-78.

Surányi D. (1990a): Onthogenetic characteristics in flowers of some plum cultivars. Part I. Acta Bot. Hung. 37: 161-182.

Surányi D. (1990b): Onthogenetic characteristics in flowers of some plum cultivars. Part II. Acta Hort. Hague 359: 278-286.

Surányi D. (1991): Geno- and phenotypic remarks in the flowers new plum cultivars. Acta Hort. Hague 288: 284-290.

Surányi, D. (1991-2015): Fenológiai naplók (kézirat). Gyümölcskut. Áll. Kft, Cegléd.

Surányi, D. 2000. A termesztett gyümölcsfajok-és fajták ökológiai sajátosságai, azok besorolása a Simon-féle értékszámok szerint. Acta Biologica Debrecina 11 (1): 143.

Surányi, D. 2002. Gyümölcsöző sokféleség (Biodiverzitás a gyümölcstermesztésben). Akcident Kft., Cegléd.

Surányi, D. (2005): Long term investigations of flowers and leaves on mainly non-domestica plums. Intern. J. Hort. Sci. 11 (1): 73-79.

Surányi, D. (2006): Magyarország gyümölcs-flórájának biológiaiökológiai jellemzése (Hazai vadon termő, meghonosodott, elvadult és potenciális gyümölcsfajok, valamint termesztett gyümölcsfajták értékelése). Kanitzia 14: 137-206.

Surányi D. (2006): Estimation of plum and prune cultivars with morphogenetic traits. Intern. J. Hort. Sci. 12 (2): 147-152.

Surányi, D. (2009): Lépcsőfokok - Értekezések a gyümölcstermesztés köréböl. GyDKFI, Cegléd.

Surányi D. (2011): Gyüjteményes szilvafajták sharka-érzékenysége és a fák életkora. Kert. Szől. 60 (42): 18-20.

Surányi D. (2013): Phenological and flower morphological studies on different plum and prune cultivars. Intern. J. Hort. Sci. 19 (3-4): $1-10$.

Surányi, D. (2014): Relative ecological indicators of the registrated and old historical fruit cultivars in Hungary. Acta Bot. Hung. 56 (3-4): 433-484.

Surányi, D. - Erdős Z. (2004): Comparative study of plum cultivars belonging to different taxons during 1980-1996. Intern. J. Hort. Sci. 10 (4): 13-19.

Szabó Z. (1989): Európai és japán szilvafajták virágzása, termékenyülése, társítása (kézirat). Kandidátusi értekezés, Bp.

Taylor, H. V. (1949): The plums of England. Crosby Lockwood and Son Press, London.

Terpó, A. (1974): Gyümölcstermő növényeink rendszertana és földrajza. in: Gyúró, F. (edit.) A gyümölcstermesztés alapjai. Mezőgazdasági Kiadó, Bp. p.139-219. 
Tomcsány P. (1960): Gyümölcsfajták irodalmi vonatkozásai (témadok.). Agroinform, Bp.

Tomcsányi P. (edit.) (1979): Gyümölcsfajtáink. Gyakorlati pomológia. Mezőgazdasági Kiadó, Bp.

Tóth, E. (1957): Élet-és alaktani összehasonlító vizsgálatok szilvafajtákon. Kert. Kut. Int. Közlem. 2: 11-129.

Tóth, E. (1967): Adatok a szilvafajták termesztési értékének megállapításához. Szőlő- és Gyüm. term. 3: 129-150.

Tóth, E. (1968): Szilvafajták öntermékenyülésének vizsgálata (kézirat). Kertészeti Egyetem, Bp.

Tóth, E. - Erdős, Z. - Surányi, D. (1971-1990): Fenológiai naplók (kézirat). Kert. Kut. Int., Cegléd.

Tóth, E. - Surányi, D. (1980): Szilva. Mezőgazdasági Kiadó, Bp.

Tüxen, R. - Ellenberg, H. (1937): Die systematische und ökologische Gruppenwer. Mitt. flor.-soz. Arbeuitsgem. Niedersachsen 3: 171-184.
Visy, Zs. (edit.) (2003): Magyar régészet az ezredfordulón. NKÖM Teleki László Alapítvány, Bp.

V. Németh, M. (1986): The virus, mycoplasma and rickettsia diseases of fruit trees. Akadémiai Kiadó, Bp.

Vondraček, J. (1975): The study of some phenophases in plums. Acta Hort. Hague 8: 23-34.

Zólyomi B. (1964): Methode zur ökologischen Characterisierung der Vegetation seinheiten und zum Vergleich der Standorte. Mathematisch-statistische Bearbeitung der Beispiele von I. Précsényi. Acta Bot. Hung. 10: 377-416.

Zólyomi B. (1987): Coenotone, ecotone and their role in the preservation of relic species. Acta Bot. Hung. 33: 3-18.

Zólyomi, B. - Baráth, Z. - Fekete, G. - Jakucs, P. - Kárpáti, I. - Kárpáti, V. - Kovács, M. - Máthé, I. (1967): Einreihung von 1400 Arten der ungarischen Flora in ökologischen Gruppen nach TWR-Zahlen. Fragmenta Bot. Mus. Hist. Nat. Hung. 4: 101-142. 